\title{
The use of hyperbaric oxygen therapy in acute hearing loss: a narrative review
}

\author{
A. B. Bayoumy ${ }^{1}$ (D) J. A. de $\mathrm{Ru}^{1,2}$
}

Received: 21 March 2019 / Accepted: 8 May 2019 / Published online: 20 May 2019

(c) The Author(s) 2019

\begin{abstract}
Introduction Acute hearing loss can have a major impact on a patient's life. This holds true for both acute acoustic trauma (AAT) and idiopathic sudden sensorineural hearing loss (ISSHL), two devastating conditions for which no highly effective treatment options exist. This narrative review provides the rationale and evidence for HBOT in AAT and ISSHL.

Methods Narrative review of all the literature available on HBOT in acute hearing loss, studies were retrieved from systematic searches on PubMed and by cross referencing.

Discussion First, the etiological mechanisms of acute hearing loss and the mechanism of action of HBOT were discussed. Furthermore, we have provided an overview of 68 studies that clinically investigated the effect of HBOT in the last couple of decades. For future studies, it is recommend to start as early as possible with therapy, preferably within $48 \mathrm{~h}$ and to use combination therapy consisting of HBOT and corticosteroids.

Implications for practice HBOT has been used quite extensively for acute hearing loss in the last couple of decades. Based on the amount of studies showing a positive effect, HBOT should be discussed with patients (shared decision making) as optional therapy in case of AAT and ISSHL.
\end{abstract}

Keywords Acute hearing loss $\cdot$ Acute acoustic trauma $\cdot$ Idiopathic sudden sensorineural hearing loss $\cdot$ Hyperbaric oxygen therapy

\section{Introduction}

Acute hearing loss can have a major impact on a patient's life. This holds true for both acute acoustic trauma (AAT) and idiopathic sudden sensorineural hearing loss (ISSHL), two devastating conditions for which no highly effective treatment options exist [1,2].

In the US Army over a 2-year period, more than 882 hearing impairments were caused by AAT, and the incidence of ISSNL in the USA was estimated to be 27 per 100,000, which corresponds to more than 66,000 new cases per year $[3,4]$.

J. A. de Ru

J.A.deRu@umcutrecht.nl

1 Department of Otorhinolaryngology, Central Military Hospital Utrecht, Ministry of Defense, Lundlaan 1, 3584 EZ Utrecht, The Netherlands

2 Department of Otorhinolaryngology, University Medical Center Utrecht, Utrecht, The Netherlands
The amount of hearing loss in AAT can vary between individuals and is based on the amount and duration of noise exposure [5]. For ISSHL, the amount of hearing loss can vary from $30 \mathrm{~dB}$ at three frequencies, to even losses of $120 \mathrm{~dB}$ at more frequencies [6]. For smaller losses, the natural course might be favorable due to the-albeit limited-repair capacity of the cochlea; however, in profound cases the chance of complete recovery is rather low. Furthermore, in case of AAT a temporary threshold shift can occur, which makes it difficult to immediately evaluate the amount of damage and subsequently the amount of recovery [7]. The definitions of 'complete recovery', 'good recovery', and other terminology were not used unambiguously in literature making comparison between studies or pooling of results difficult.

The cochlea is an organ with an impressive activity; therefore, it is always dependent on adequate oxygen levels in the blood [8]. However, because of the protected location of the cochlea in the temporal bone, blood supply is limited [9]. One of the mechanisms playing a possible role in both AAT and ISSHL is of vascular origin: lack of oxygen. For 
AAT, Misrahy et al. [10] found evidence for the vascular theory in 1958. They reported cochlear endolymphatic hypoxia during noise exposure and interpreted this as caused by a reduced cochlear blood flow. Numerous studies have later demonstrated signs of reduced blood flow due to vasoconstriction and cochlear hypoxia in AAT [11-16]. In ISSHL, this vascular etiology was described by Ruben et al. [17]. Other authors since then have also found a vascular etiology for sudden deafness [18-24].

All this has led to the experimental use of vasoactive drugs and other therapies that tried to nullify the hypoxia. Unfortunately, none of those therapies was proven effective [25]. Already in 1956, Boerema, the father of modern hyperbaric medicine, was the first to describe the use of hyperbaric oxygen therapy (HBOT) in combination with cardiac surgery [26]. During HBOT, 100\% oxygen is inhaled at a pressure of about $200-300 \mathrm{kPa}$, in sessions of $2-3 \mathrm{~h}$ per day, for about 10-25 days. This is almost sufficient to supply the resting total oxygen requirements of many tissues without a contribution from oxygen bound to hemoglobin. HBOT may increase the oxygen load to the cochlea, eradicating hypoxia. Despite the above-mentioned rationale for therapy, not everyone is convinced of the efficacy of HBOT. This is probably because of the fact that most physicians are not very well acquainted with this therapy and certainly not for this indication. However, according to the Cochrane Library, no other specific drug therapy has been documented to be proven effective against hearing loss in case of AAT or ISSHL. In recent years, HBOT has been used for AAT and ISSHL by many colleagues; however due to the lack of randomized controlled trials, it is still unclear what the role of HBOT should be in the treatment protocol of these two types of acute hearing loss [27]. This narrative review provides the rationale and evidence for HBOT in AAT and ISSHL.

\section{Etiological mechanism of hearing loss}

\section{The first reports on hypoxia and hyperbaric oxygen therapy}

Some 40 years ago, the first steps were made in understanding the theoretical framework for HBOT in inner ear disease. First, it was reported that in conditions of low oxygen, the cochlear potential diminished and failed to reappear after restoration of the blood supply [28]. In a lower oxygenated state, the cochlear potential was found to be $20 \mathrm{mV}$ more negative than in the oxygenated state [29].

Noise induces a decline of oxygen pressure in the perilymph of the scala tympani by more than half [30].

Another report by Scheibe et al. found that oxygenation of the cochlear perilymph decreased by $20 \%$ during highintensity acoustic exposure (125 dB) [31]. Also, in case of
ISSHL, it was found that the perilymphatic oxygen tension was low [32].

In a review on seven experimental studies performed by Axelsson and Dengerink, it was concluded that noise induces a reduction in cochlear blood flow [33-41]. In the following years, other authors found the same conclusion. Yamane et al. reported blood stagnation in the strial capillaries, leading to strial dysfunction, after acoustic trauma in guinea pigs [16]. In 1992, Quirk et al., observed capillary vasoconstrictions and decreased red blood cell velocity after noise exposure $(110 \mathrm{~dB})$ with intravital microscopy in vivo [13].

Due to all the experimental findings that suggested a correlation between low oxygen levels in the inner ear and the pathogenesis of hearing loss, experiments with the use of HBOT were performed.

In 1982, Lamm et al. assessed the effects of HBOT in an experimental AAT model in guinea pigs. They showed an alleged preventive effect of HBOT in 14 out of 26 guinea pigs [42].

$\mathrm{Hu}$ et al. reported that HBOT can reduce the noiseinduced threshold shift and decrease cochlear damage during chronic noise exposure in guinea pigs [43].

\section{Mechanically induced hair cell damage}

Intense noise produces mechanical damage to the cochlea, which directly leads to disruption of the hair cell stereocilia [44, 45]. Threshold shifts (auditory-nerve responses) are correlated with the amount of damage or loss in hair cells after acoustic trauma [46]. Pilgramm et al. demonstrated in an animal model that $60 \mathrm{~h}$ after acoustic trauma, the number of inner ear sensory cells that had suffered morphological damage was lower in the group receiving HBOT than in the group without HBOT [47]. Kuokkanen (1997) and (2000) showed a lesser amount of threshold shift and fewer missing hair cells among rats that were treated with HBOT following 60 shots $(162 \mathrm{~dB})$ with an assault rifle $[48,49]$.

Colombari et al. found in an animal experiment with acute acoustic damage that the number of injured cochlear outer hair cells decreased and that their functionality improved after HBOT [50].

\section{Reactive oxygen species}

Due to reduction of the blood flow, reduced oxygen supply causes the phosphorylation process within the mitochondria to become inefficient. This causes the formation of reactive oxygen species (ROS) as a by-product of metabolism. In 1995, Yamane et al. published a study on the formation of free radicals within the inner ear directly after acoustic trauma [51]. Ohlemiller et al. found a nearly fourfold increase in ROS levels in animals after noise exposure 
compared to non-exposed animals [52]. Ohinata et al. observed increased 8-isoprostane levels, which serve as an accurate marker for free radical-catalyzed lipid peroxidation [53] during noise exposure and these levels diminished directly after the termination of exposure [54]. Furthermore, ROS play an important role in the local inflammation caused by noise-induced damage. After ROS formation in the cochlea, interleukin-6 and tumor necrosis factor alpha were found to be produced locally. These pro-inflammatory cytokines can themselves produce damage to the cochlea [55-57]. Also, ROS formation activates the c-Jun N-terminal kinase (JNK) signaling pathway [58]. The JNK signaling pathway and mitogen-activated protein kinase (MAPK) pathways are increased after acoustic trauma; these pathways mediate programmed apoptosis of outer hair cells [59]. Han et al. reported that apoptosis inducing factor (AIF) and endonuclease $\mathrm{G}$ (endoG) were found in the nucleus of apoptotic hair cells [60].

Following ischemia, the blood flow may recover and consequently the availability of oxygen rises, and as a result of this reperfusion more ROS may be formed [51].

Therefore, safety concerns have been raised for HBOT, since the higher availability of oxygen within the inner ear may further boost the formation of ROS. Arslan et al. did an experiment in which they measured pro-inflammatory cytokines and hearing levels in rats exposed to acoustic trauma. They found that treatment with HBOT in the first $3 \mathrm{~h}$ after acoustic trauma resulted in significantly higher IL-1 $\beta$ levels compared to the control group. The group in which HBOT was started within $24 \mathrm{~h}$ after acoustic trauma had no significantly different pro-inflammatory mediators compared to the control group, and had significantly better post-treatment auditory brain stem responses compared to the other groups [61].

Kahraman et al. exposed 16 rats to noise of $110 \mathrm{~dB}$ for 1 h. All rats, except those in the control group, were treated with immediate HBOT within $1 \mathrm{~h}$ of noise exposure. They obtained lower hearing gains in the HBOT groups compared to the control group. However, in the group in which HBOT was combined with corticosteroids, significant recoveries were found. This study highlights the negative effects of the extremely early initiation of HBOT and the importance of combining HBOT and corticosteroids, in terms of better recovery [62]. In clinical practice, however, it would not be possible to initiate HBOT on such a short notice. Thus, HBOT combined with corticosteroids can be deemed safe when used at least $24 \mathrm{~h}$ after the onset of hearing loss.

Moreover, it has been found by Hamernik et al. that the hair cell death after noise exposure is relatively small, but that the loss of hair cells increases over a period of 2-30 days after exposure [63]. In line with this, Yamashita et al. found a correlation with the delayed formation of ROS and the progressive hair cell loss, which stabilized after 2 weeks [64].

Therefore, based on the evidence provided above, HBOT may play a very important role in the early prevention of further damage to the hair cells caused by the reduction of cochlear blood flow and formation of free radicals. But, a reduction of the inflammatory reaction might also be necessary. Takemura et al. indeed found protective effects of dexamethasone infusion in guinea pigs after acoustic trauma, attributed to the attenuation of the threshold shift and increase in hair cell preservation [65].

Extensive reviews on the etiological mechanisms of AAT have been performed by Kurabi (2017), Wong (2015), Shi (2011) and Henderson (2006) [9, 66-68].

\section{Clinical use of hyperbaric oxygen therapy}

Since the late 1960s, HBOT has been experimentally used in clinic for AAT and ISSHL as well. Appaix [69] and Lamm [70] are credited for their pioneering work on the role of HBOT in these two conditions. In 1976, De Heyn and van Opstal treated two series of patients following AAT, one group with vasodilators and the other with a combination of vasodilators and hyperbaric oxygen. They found better results in the patients with the combination therapy [71]. Vincey reported on the rationale for HBOT inner ear disease in 1978 [72]. In 1979, Goto et al. performed a study on 91 patients suffering from ISSHL, of whom 20 patients were treated with a combination of vasodilators, corticosteroids, vitamins, stellate ganglion block and HBOT. All patients in this treatment group had improved hearing $(>10 \mathrm{~dB})$ and $40 \%$ had recovered completely [73].

In 1981, Demaertelaere and van Opstal published a study in the Dutch language on the treatment of AAT with HBOT [74]. Vavrina and Muller published a similar study in French in 1995 [75]. Pilgramm and Schumann published a series of 122 soldiers following AAT [76]. These patients were randomly allocated to different treatment groups. The authors of these studies were positive about the results of HBOT in AAT patients. Regarding AAT, Winiarski et al. found significant differences on 4, 6 and $8 \mathrm{kHz}$ when HBOT was started within 5 days in patients suffering from AAT [77]. Three years later, in 2008, Ylikoski et al. published the results of a study in which HBOT monotherapy was compared to normobaric oxygen therapy in a cohort of AAT patients, who were exposed to firearm shooting. They reported significantly higher hearing gains in the HBOT group compared to the normobaric group (69.3 vs $56.2 \%, P<0.001$ ) [78].

Since 1998, when Lamm et al. [79] and Nakashima et al. [80]. published positive clinical results of HBOT for ISSHL in the English language, a storm of articles was published in 
the first decade of this century, by Aslan et al., Racic et al., Topuz et al., Narozny et al., Horn et al., Desloovere et al., Dundar et al., Fujimura et al. and Muzzi et al., confirming the earlier outcomes [81-89].

Negative results were published by Kestler et al. [90]. in a German study in 2001, and by Satar et al. [91]. who found that the hearing gains in the HBOT and control group were $35.5 \mathrm{vs} 37.0 \mathrm{~dB}(P=0.754)$. They also found that the hearing improvement (gain $>10 \mathrm{~dB}$ ) was $60 \%$ in the HBOT group and $76.4 \%$ in the control group $(P=0.364)$. But, when calculating the relative gain using the data mentioned in their manuscript, it was $52.1 \%$ for the HBOT group and $45.0 \%$ for the control group.

\section{Steroid therapy}

As described above, both in case of AAT and ISSHL, an inflammatory response occurs as part of the pathophysiology $[66,92,93]$. Therefore, it is deemed necessary to stop the inflammatory reaction. The first randomized controlled study with corticosteroids for ISSHL was performed by Wilson et al. in 67 patients. They found that patients treated with corticosteroids had statistically higher recovery than the placebo group (61\% vs $32 \%$ ). Complete recovery in their study was defined as: "hearing within $10 \mathrm{~dB}$ of pre-hearing loss speech reception or averaged pure tone score. Partial recovery of hearing to $50 \%$ or more of the pre-hearing loss speech reception score or average pure tone score" [94].

Corticosteroids increase oxygen consumption by mobilizing amino acids for gluconeogenesis and by altering glucose utilization by oxygen-consuming mechanisms [95]. This higher oxygen consumption may enhance the decline of the partial oxygen pressure in the perilymph, as observed in animals exposed to noise and treated with corticosteroids [96]. Therefore, adding HBOT to corticosteroids might be indicated on theoretical grounds, so one might ask: does combining corticosteroids and HBOT potentiate the effect of corticosteroids monotherapy? In an experimental animal study on AAT, D'Aldin et al. found that combination therapy in animals with HBOT and corticosteroids significantly improved threshold shifts compared to the control group receiving only corticosteroids [97]. In the same year, similar results were found by Lamm and Arnold who concluded that the combination of HBOT and prednisolone had a better therapeutic effect on noise-induced hearing loss in guinea pigs than HBOT or prednisolone as monotherapy [12].

Also Fakhry et al. stated that combined HBOT and corticosteroid therapy provided more protection in vivo from acoustic trauma, especially when started within 1 day following the exposure [98].

During the last decade, even more clinical evidence suggested that combination therapy HBOT and corticosteroids results in better recovery than both treatments alone. For example Alimoglu et al. [99] obtained higher hearing gains and higher response to therapy in ISSHL patients treated with combination therapy compared to those therapies as individual entities, while Capuano et al. [100] reported that the combination therapy with HBOT and intravenous corticosteroids had significantly higher mean gains at $0.5,1,2$ and $4 \mathrm{kHz}$ compared to both HBOT and intravenous corticosteroids as monotherapies in patients with ISSHL. Still, more studies can be traced in which HBOT was combined with corticosteroids [73, 75, 81, 83, 88, 91, 99-127].

\section{Recent findings}

In 2019, Bayoumy et al. reported the positive effects of HBOT and corticosteroids compared to corticosteroid monotherapy in a cohort of AAT patients. Absolute $(21.3 \mathrm{~dB}$ vs $11.6 \mathrm{~dB})$ and relative $(57.6 \%$ vs $31.4 \%$ ) hearing gains were statistically significantly in favor of HBOT therapy. They found a higher percentage of patients recovering to an acceptable level for the Dutch Armed Forces in the HBOT group [126].

In 2018, six studies investigating the effect of HBOT and corticosteroids in ISSHL were published. Interestingly enough, these latest studies have a higher evidential level due to better adherence to methodological regulations as compared to many of the previous reports.

Chi et al. treated 30 patients with only medical therapy (pentoxifylline, dextran and corticosteroids) and 30 patients with conventional therapy plus additional HBOT. In both groups, therapy was initiated early, on average within 4 days. Complete hearing recovery was significantly better in the HBOT group after 180 days (27\% vs $10 \%, P=0.043)$ [121].

Almosnino et al. investigated two groups of patients receiving intratympanic or oral corticosteroids (control) compared to the same treatments with additional HBOT. They observed hearing gains of $17.9 \mathrm{~dB}$ in the HBOT group, and $15.0 \mathrm{~dB}$ in the control group. They concluded that HBOT did not show a beneficial effect over therapy with corticosteroids. However, HBOT was initiated till even as much as 3 months after hearing loss [122].

Krajcovicova et al. performed a prospective study in 68 patients suffering from ISSHL, in which 47 were treated with additional HBOT. They found a hearing improvement rate (defined as hearing $\geq 10 \mathrm{~dB}$ ) of $61.7 \%$ in the HBOT group, compared to only $28.6 \%$ in the control group. The average hearing gain in the HBOT group was $20 \mathrm{~dB}$, whereas in the control group it was $8.5 \mathrm{~dB}$. Treatment was initiated within 7 days [123].

Cho et al. compared one group treated with systemic and intratympanic corticosteroids to another group with the same treatments plus HBOT. They found significantly higher word discrimination scores in favor of the HBOT group (66\% vs $13 \%, P=0.029)$. The absolute hearing gains between the 
HBOT and control group was not significantly different (47.3 dB vs $37.7 \mathrm{~dB}, P>0.05)$ [124].

Khater et al. treated 11 patients with medical therapy (systemic corticosteroids, intratympanic corticosteroids, antiviral therapy) and 11 patients with medical therapy plus HBOT. The absolute hearing gain was significantly higher in the HBOT group compared to the control group ( $54.8 \mathrm{~dB}$ vs $43.8 \mathrm{~dB}, P=0.0014)$. Regarding recovery, 8 out $11(73 \%)$ of HBOT patients showed total improvement at all frequencies, while only 6 out of $11(46 \%)$ showed total improvement in the control group; however, this difference was not significant $(P>0.05)$ [125].

Hosokawa et al. compared three different treatment strategies: HBOT and systemic corticosteroids vs intratympanic corticosteroids and systemic corticosteroids vs systemic corticosteroids alone. They mentioned that the complete recovery rates were $26.1 \%$ in the HBOT group, $8.6 \%$ in the combined corticosteroids group and $6.3 \%$ in the systemic corticosteroids group. The overall recovery was $78.3 \%$ for the HBOT group, $48.6 \%$ for the combination corticosteroids group and $32.5 \%$ for the systemic corticosteroids group. Treatment was initiated within 4.5 days after onset of hearing loss [127].

Thus, it seems, based on recent evidence, that addition of HBOT to corticosteroids may be beneficial, especially when initiated early, in both AAT and ISSHL. Furthermore, Table 1 shows the outcomes of the performed studies in AAT and ISSHL performed in the last decades.

\section{Intratympanic vs systemic corticosteroids}

Alimoglu et al. found that systemic corticosteroids had significantly higher hearing gains and complete recovery (63.8\% vs $46.5 \%$ ) compared to intratympanic corticosteroids, when both drug delivery methods were combined with HBOT [99]. Sevil et al. compared two different steroid delivery strategies (intravenous and intratympanic) with HBOT for patients with ISSHL. They found no differences between the two delivery strategies. Naiboğllu et al. found that addition of intratympanic corticosteroids to HBOT with systemic corticosteroids does not result in better recovery [112].

So it seems that intratympanic delivery of corticosteroids does not have benefit over systemic corticosteroids. But, when systemic corticosteroids are contraindicated in a subgroup of patients, intratympanic corticosteroids can be considered as substitute therapy. In literature, the use of intratympanic steroids as first-line therapy for ISSHL was found to be superior to placebo therapy with intratympanic saline injections in a randomized, triple-blind, controlled trial [128].

\section{Early initiation of treatment}

For acute losses, the acute initiation of therapy seems logical and many authors found that early treatment is beneficial. In AAT, Salihoglu et al. compared two groups: one group was treated within 10 days and the other one after 10 days. The early therapy initiation group was significantly better on 6,8 , $12.5,14$ and $16 \mathrm{kHz}$ compared to the late initiated treatment group [129]. Lafère et al. found significantly higher hearing gains in the HBOT groups of patients suffering from AAT that started therapy within 6-43 h compared to the control group that received corticosteroid therapy within $48 \mathrm{~h}$ [103]. In line with these results, Bayoumy et al. [126] concluded that early initiation within 2 days of acoustic trauma with HBOT had significantly higher relative hearing gain compared to the same treatment started after 2 days.

Capuano et al. found that recovery was significantly better when patients were treated with HBOT in the first 14 days after ISSHL, than those treated after 14 days [100]. Holy et al. described that patients who were treated with HBOT within 10 days had significantly more improvement than those treated later than 10 days (66\% vs 39\%) [130].

Nakashima et al. reported that the final hearing level in patients treated with HBOT within 1 week from the onset of ISSHL was better than in those patients who were treated after 1 week [80].

Yildirim et al. found significantly higher gains in patients treated within 14 days after onset of hearing loss with HBOT, corticosteroids and piracetam, compared to patients who were treated after 14 days [110].

Hosokawa et al. reported significantly higher improvement rates in patients who were treated within 7 days (82.2\%) of onset, compared to patients who were treated more than 7 days $(42.7 \%, P<0.001)$ after hearing loss [131].

Xie et al. showed that in patients who recovered from hearing loss, HBOT was initiated on average 5.6 days after onset of symptoms, whereas the non-recovered patients were treated on average after 9.1 days $(P=0.003)$ [120].

This highlights the importance of early intervention with HBOT. Therefore, it is recommended for both AAT and ISSHL that treatment with HBOT is started as early as possible.

An interesting side-step was published by Karatop-Cesur et al. who reported a negative correlation between the negative early treatment response $(<10 \mathrm{~dB}$ hearing gain in the first week) and failure of HBOT. In other words, when the hearing gain in the first week was less than $10 \mathrm{~dB}$, then the probability of HBOT failure was higher [132].

\section{Severity of hearing loss}

The severity of hearing loss may also play a role when choosing HBOT, as investigated by some authors. Fattori 


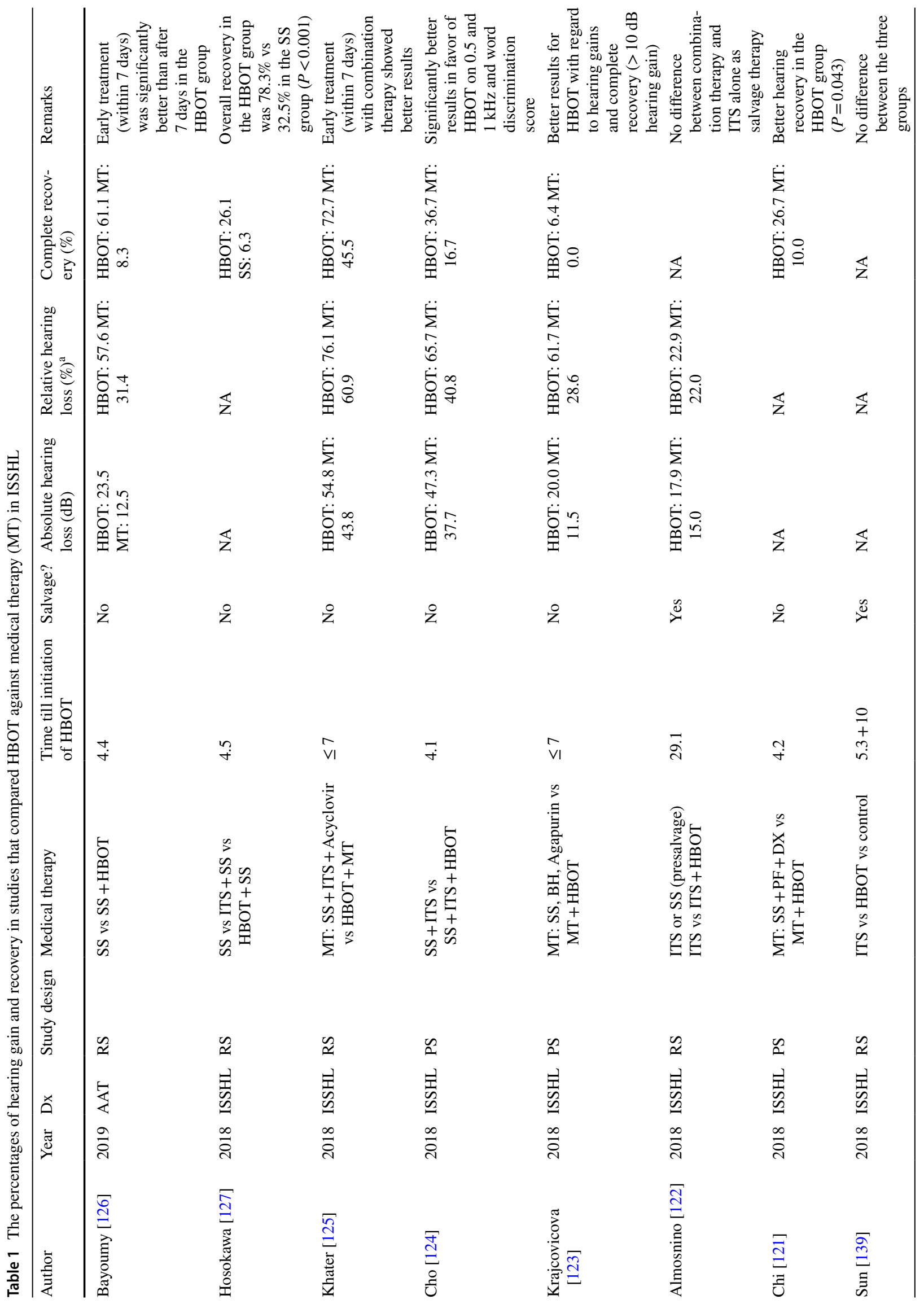




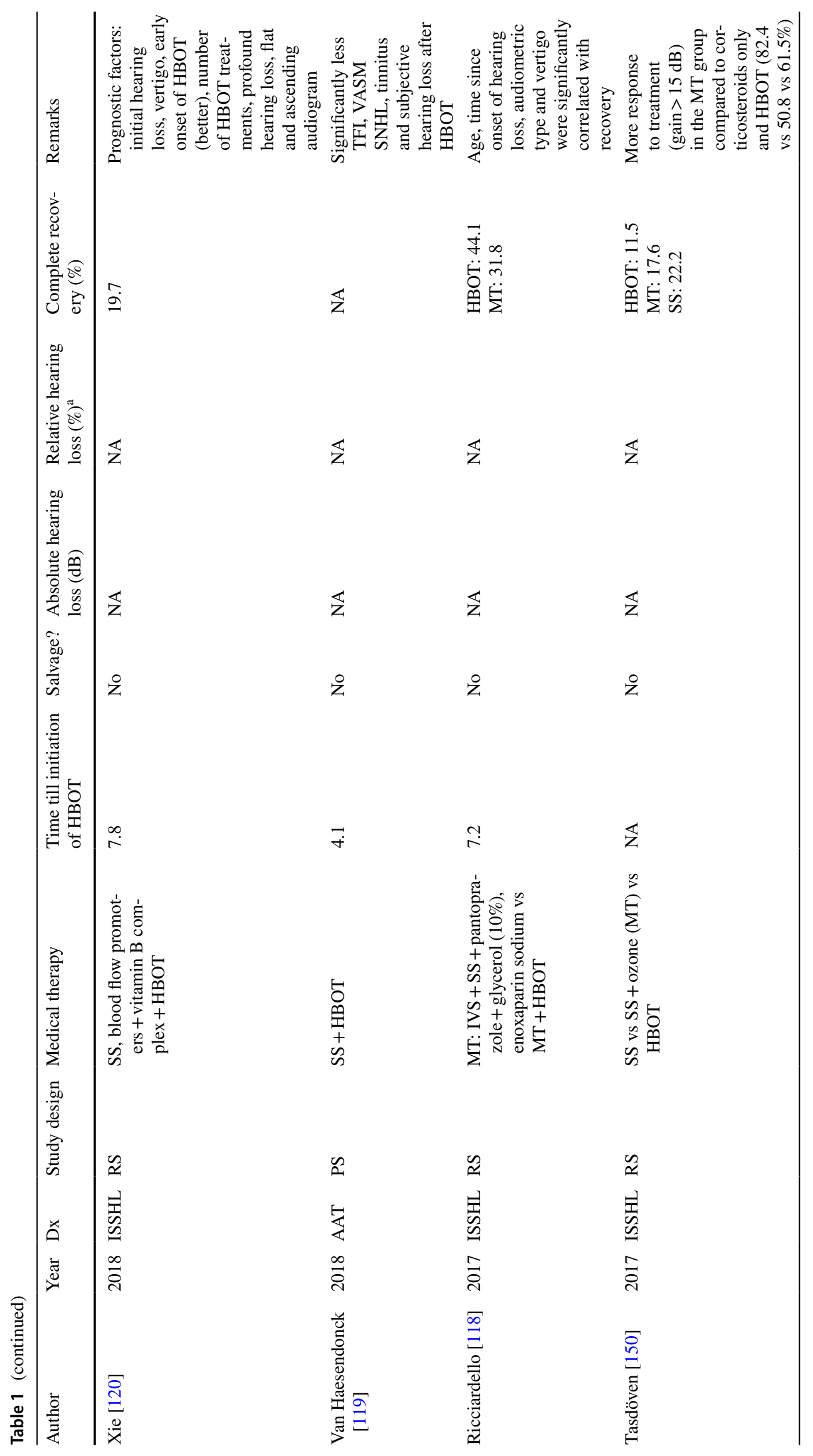




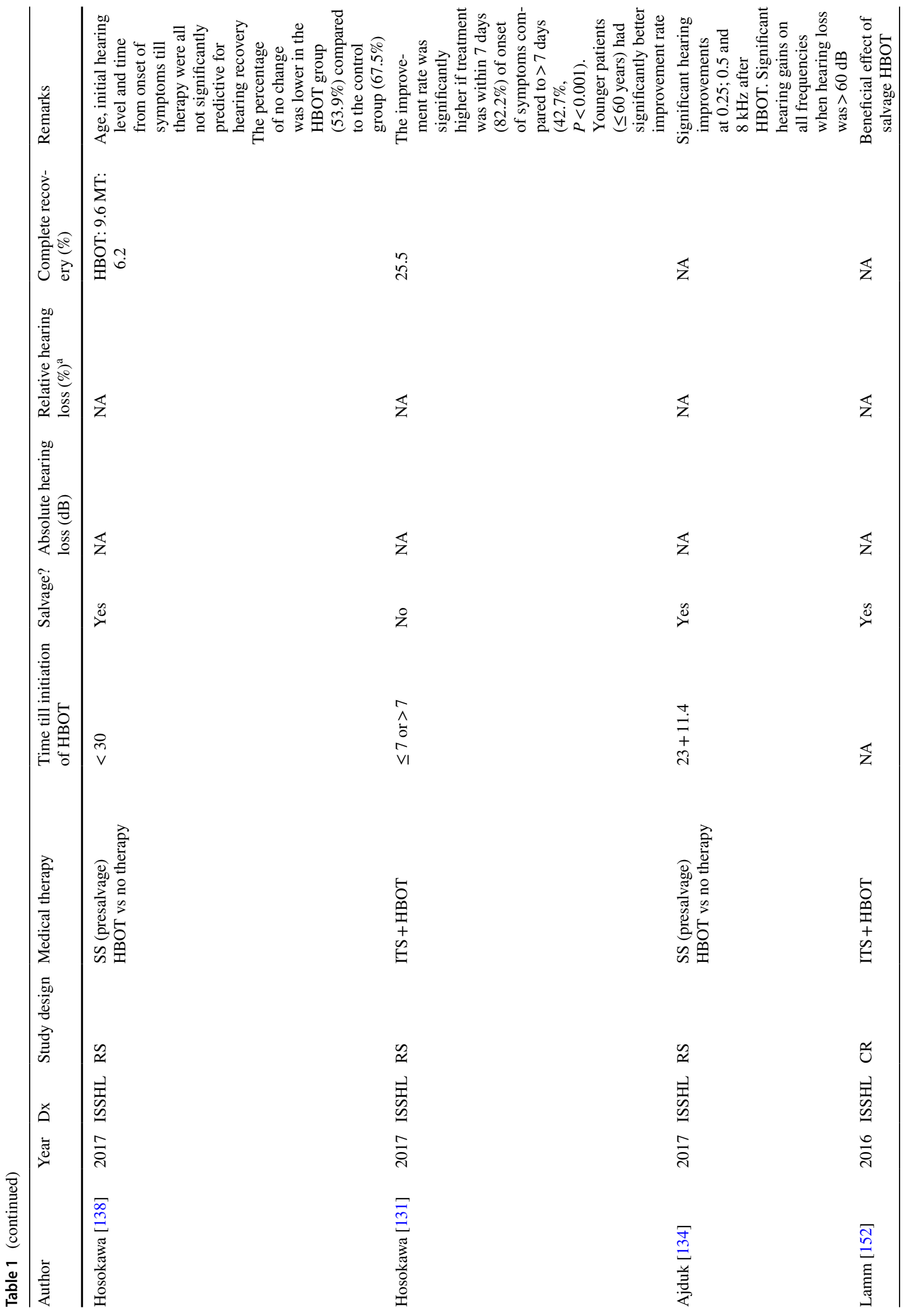




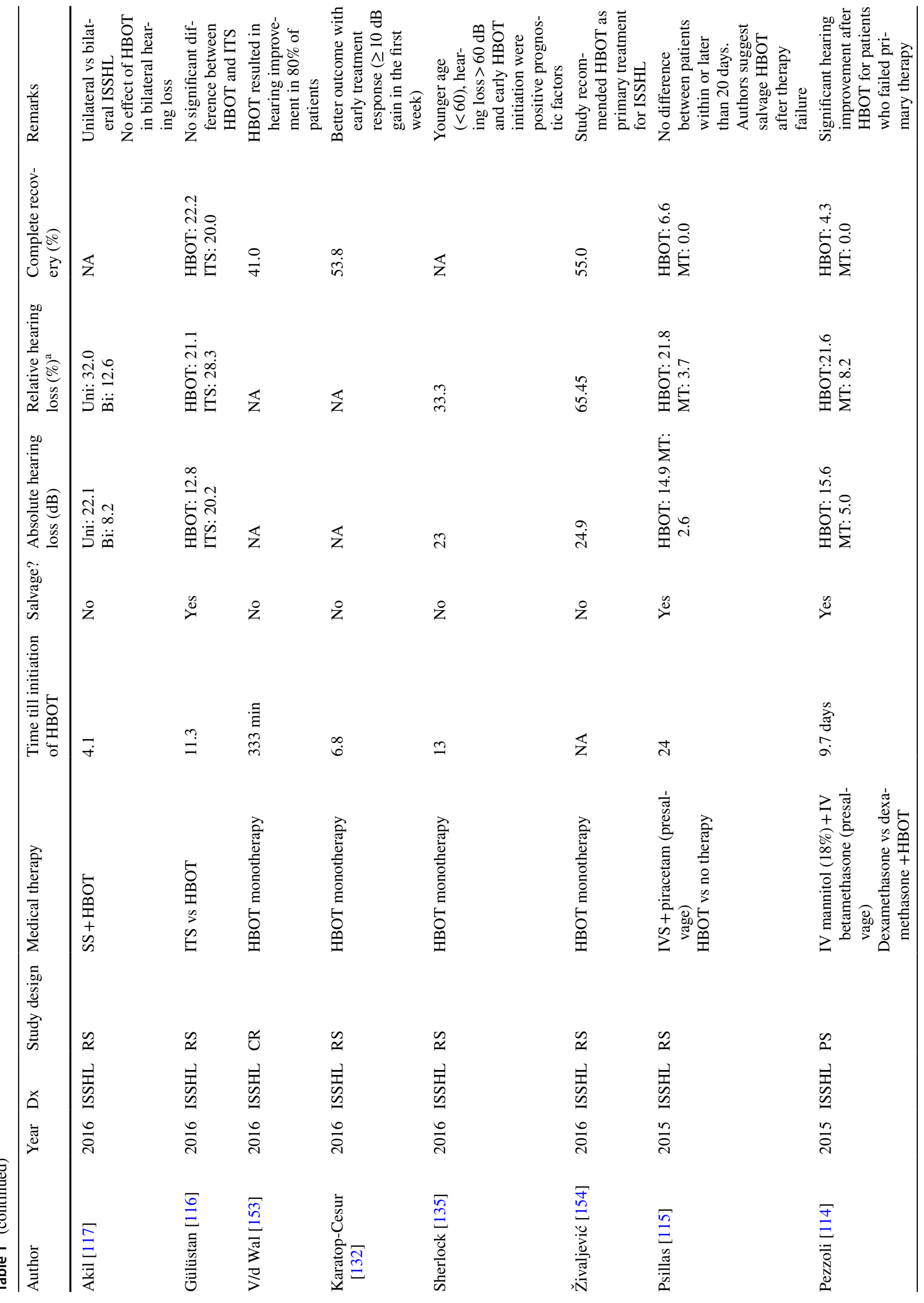




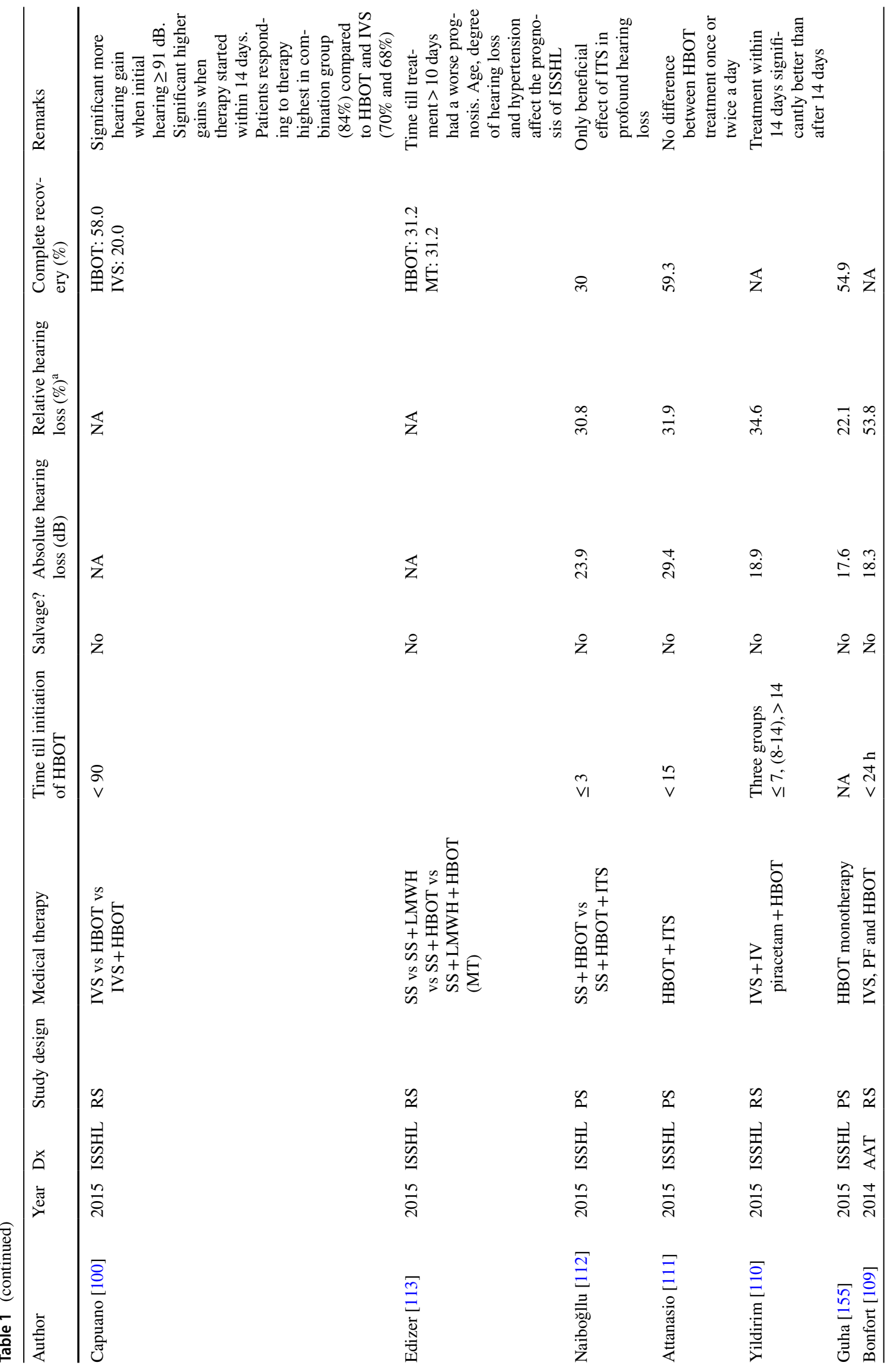




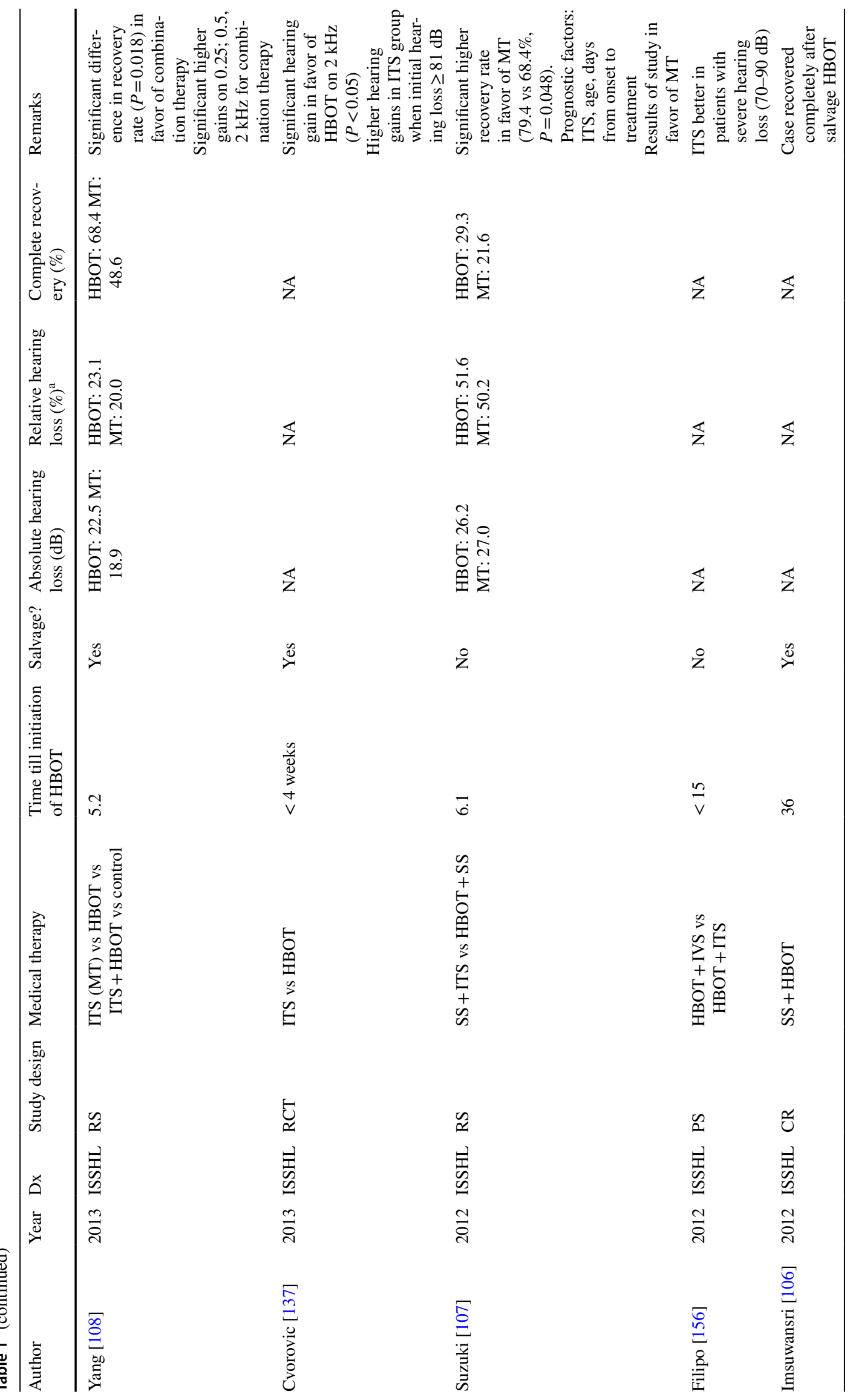




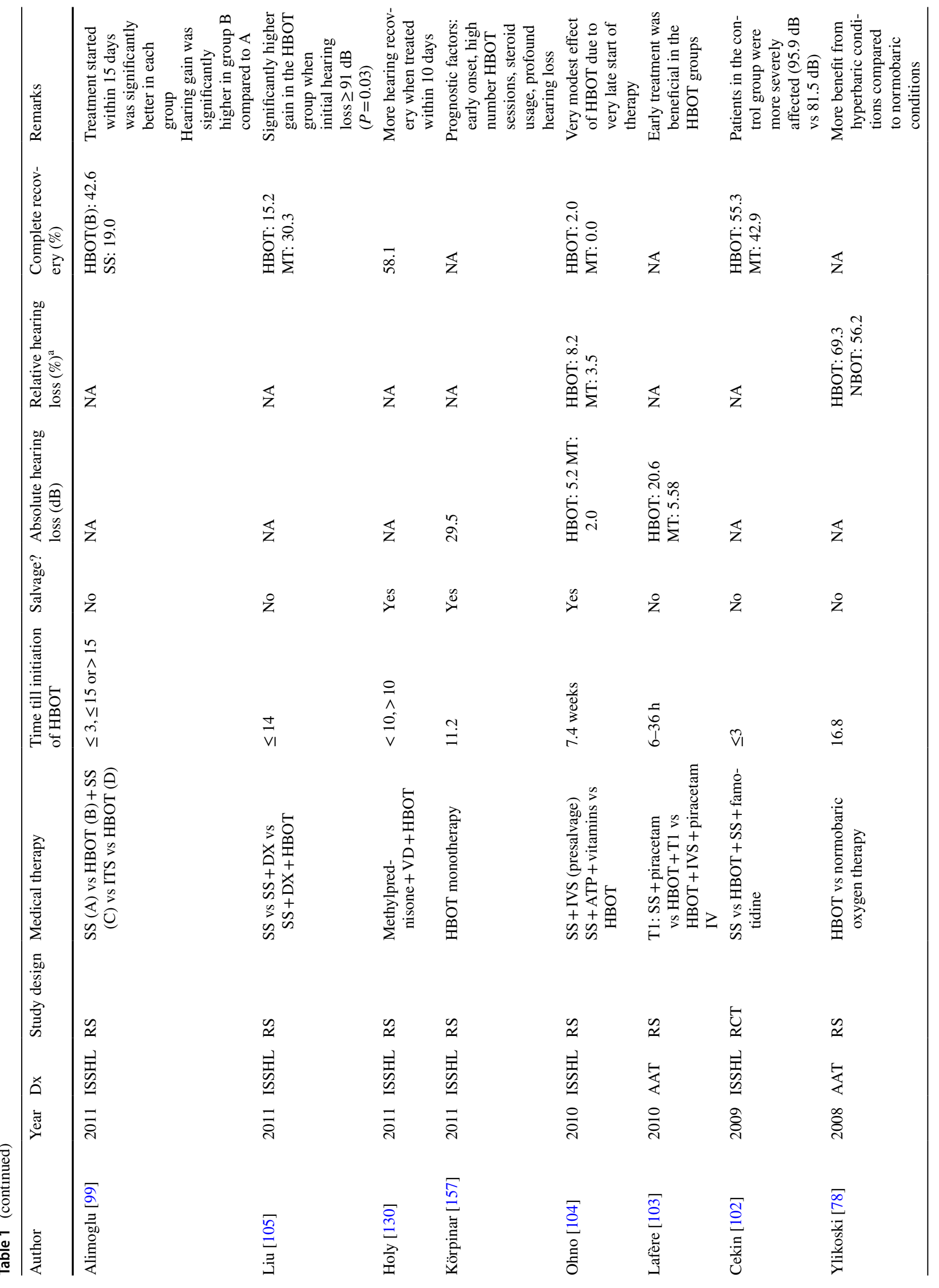




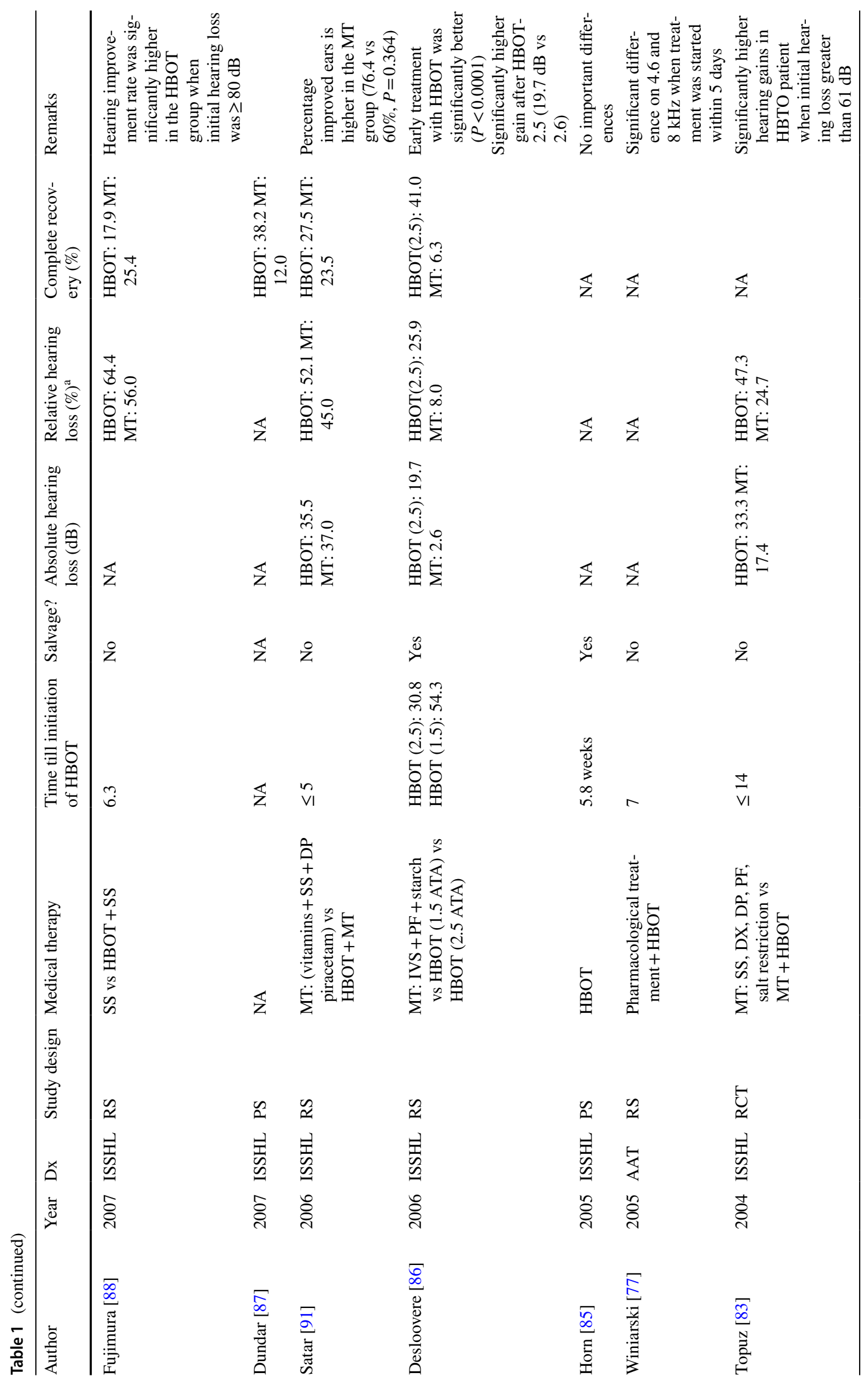




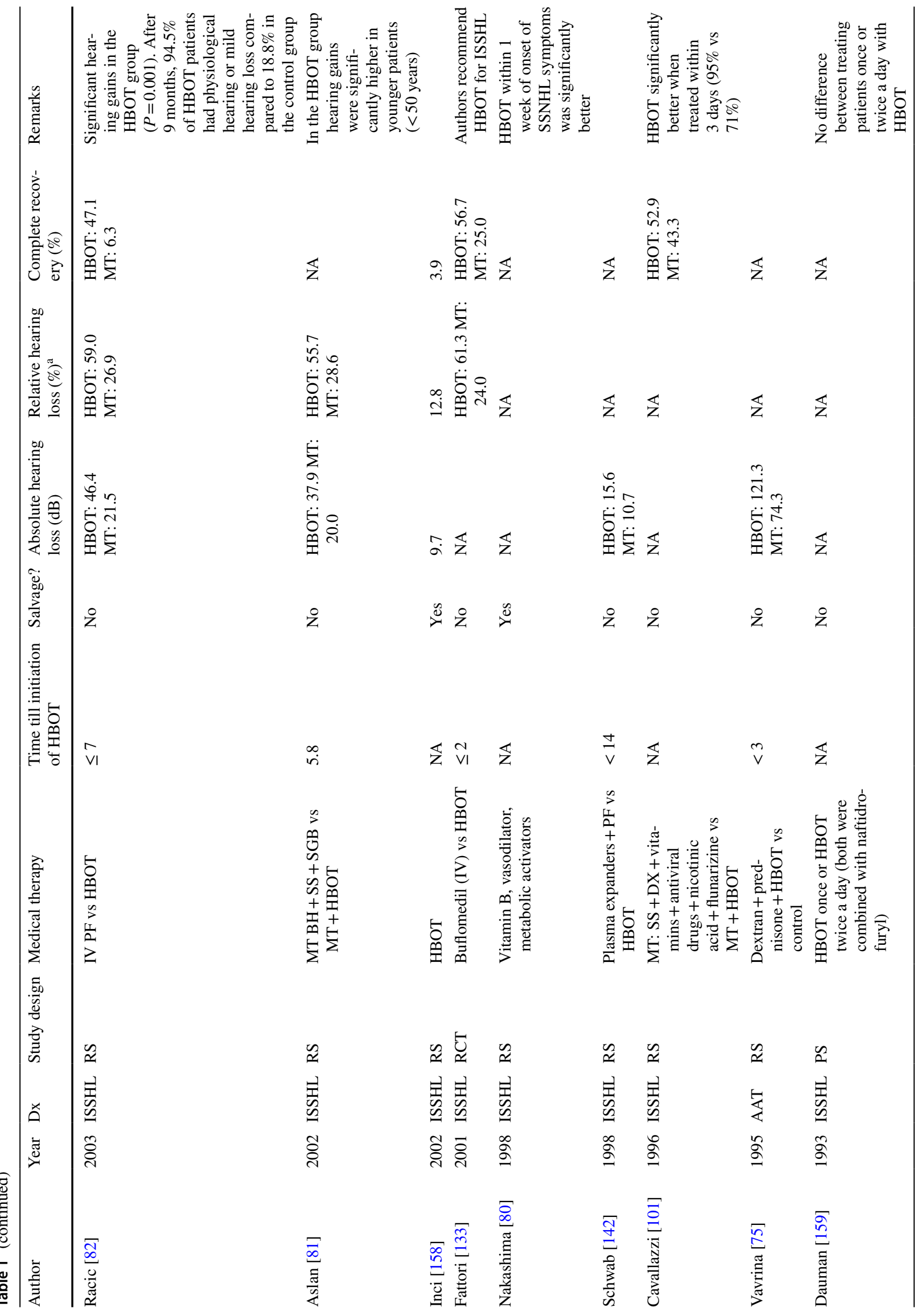




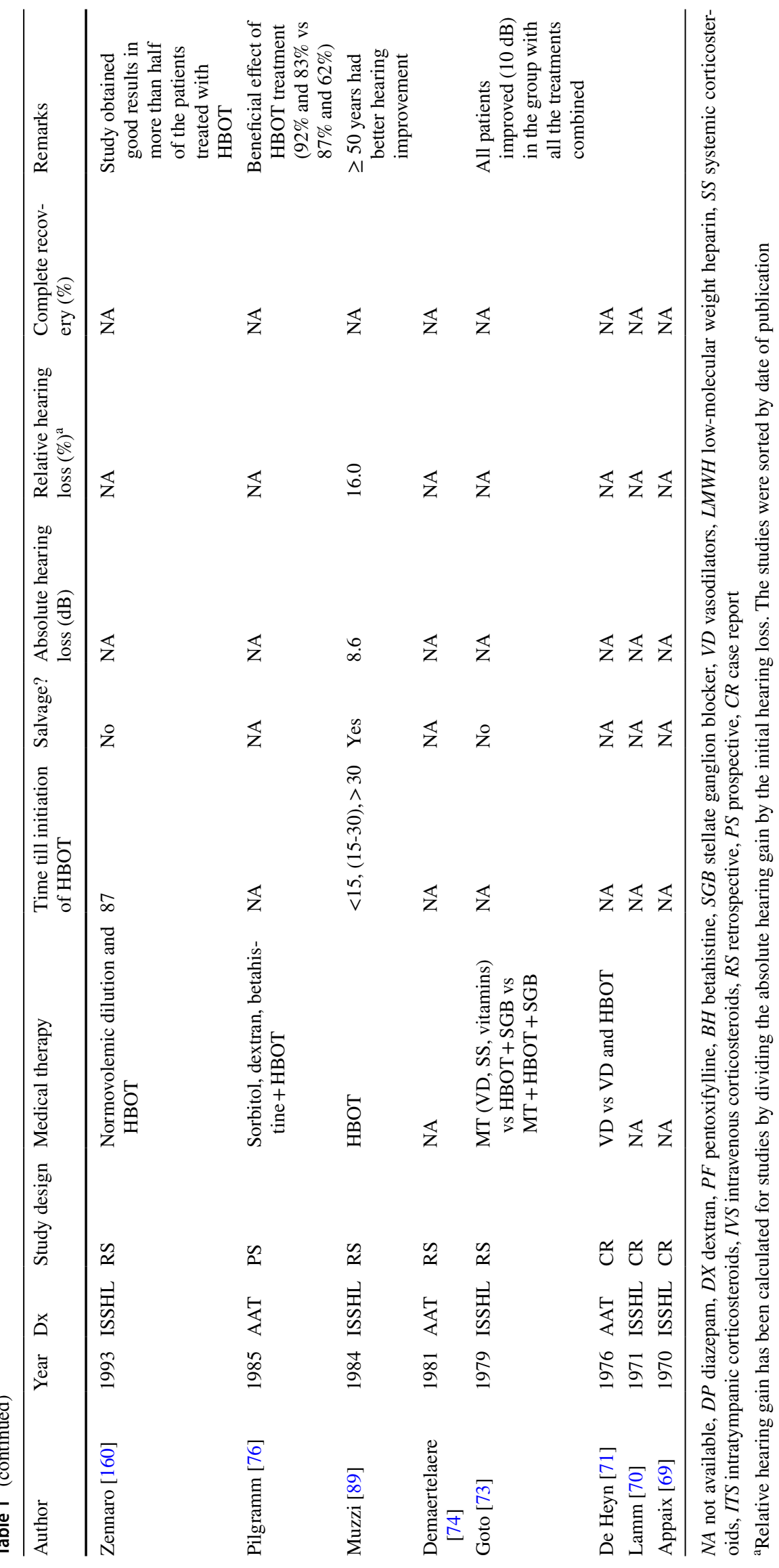


et al. obtained a significantly greater improvement in nine patients with severe hearing loss $(>70 \mathrm{~dB})$ compared to ten patients with mild hearing loss $(\leq 40 \mathrm{~dB})$. Patients were treated within $48 \mathrm{~h}$ after the onset of hearing loss [133].

Topuz et al. reported that in the group $(n=10)$ with initial hearing level $\geq 81 \mathrm{~dB}$ and in the group who had hearing levels between 61 and $80 \mathrm{~dB}(n=11)$, HBOT resulted in significantly higher hearing gains compared to their control groups ( $n=4$ and $n=11$ ) who received corticosteroids, dextran, diazepam, pentoxifylline and salt restriction as treatment. However, there was no significant difference between the treatment and control groups when the initial hearing levels were $\leq 60 \mathrm{~dB}$ ( 6 control vs 13 HBOT patients). Treatment in this study was started within 2 weeks of the onset of hearing loss [83]. Furthermore, Fujimura et al. found significant hearing improvement rates following HBOT and corticosteroids $(n=24)$ compared to corticosteroids alone $(n=12)$ in patients with an initial hearing loss of $\geq 80 \mathrm{~dB}$; this difference was not found when the initial hearing loss was smaller than $80 \mathrm{~dB}$. In this study, treatment was started on average after 6.3 days [88].

Liu et al. had significantly higher hearing gain values in the HBOT group, which consisted of 46 patients with profound hearing loss $(\geq 91 \mathrm{~dB})$, compared to the control treatment. However, in severe $(n=35,71-90 \mathrm{~dB})$ and less severe ( $n=31, \leq 70 \mathrm{~dB}$ ) hearing loss cases, this significant higher hearing gain difference was not found. Initiation of therapy occurred within 14 days after onset of hearing loss [105].

Furthermore, in 22 patients with hearing loss greater than $60 \mathrm{~dB}$, Adjuk et al. reported significant hearing gains after salvage HBOT. These results were not so pronounced in patients with hearing loss smaller than $60 \mathrm{~dB}$ (21 patients). Patients were started with HBOT on average after 23 days from the end of steroid therapy. Steroid therapy was started after 11.4 days from the onset of ISSHL, thus 34.4 days were past between the onset of symptoms and HBOT [134].

The same results were obtained by Sherlock et al., who also found that patients with initial hearing loss greater than $60 \mathrm{~dB}(n=44)$ had higher hearing gains than $\leq 60 \mathrm{~dB}$ $(n=34)$. HBOT was initiated on average 13 days after onset of ISSHL [135].

It may seem that HBOT has more beneficial effect when the hearing loss is more severe. However, this possibly just stems from the fact that the greater the loss, the more will be the effect demonstrated. Therefore, a calculation of the relative gain as described by Plontke et al. can be of great importance [136]. Another important factor might be that cases with more profound losses have lower spontaneous recovery levels and therefore treatment effects may be easier detectable or statistically significant and are more clinically relevant.

Contradictory results, however, were obtained by Cvorovic et al., who found significantly better hearing recovery in the intratympanic dexamethasone group compared to the salvage HBOT group when the initial hearing loss was $\geq 81 \mathrm{~dB}$. Therapy was started within 4 weeks after the onset of ISSHL [137].

\section{Age}

Sherlock et al. mentioned that patients younger than 50 years old had significantly higher hearing gains compared to patients older than 50 years $(27 \mathrm{~dB}$ vs $19 \mathrm{~dB})$ in a cohort of 78 HBOT patients [135].

Aslan et al. obtained significantly better results in the HBOT group in patients who were younger than 50 years (48.9 vs $14.5 \mathrm{~dB}, P<0.001$ ) [81].

Topuz et al. reported higher hearing gains in patients $\leq 50$ years compared to those older than 50 years (39.1 vs $22.8 \mathrm{~dB}, P=0.044$ ) [83]. Furthermore, Cvorovic et al. also found significantly better hearing recovery in patients younger than 60 years old treated with HBOT (40.2 dB vs $21.2 \mathrm{~dB}$ ) [137]. Edizer et al. obtained significant lower recovery in patients older than 60 years old [113].

Hosokawa et al. found significantly better improvement rates in patients who were 60 years old or younger $(74.8 \%)$ compared to patients older than 60 years $(62.9 \%, P=0.024)$ [131].

Cekin et al. did not find any differences in hearing outcomes in patients younger or older than 50 years [102].

\section{Salvage therapy}

Some studies used HBOT as a rescue or salvage therapy after failure of conventional therapy. Pezzoli et al. used HBOT as salvage therapy for patients who failed corticosteroid therapy. Although they found significant benefit for HBOT, these results were clinically very marginal [114]. Hosokawa et al. only obtained complete recovery rates of $9.6 \%$ and $6.2 \%$ in the HBOT and control groups, respectively, when HBOT was used as salvage therapy [138]. Ohno et al. found hearing gains of $5.2 \mathrm{~dB}$ and $2.0 \mathrm{~dB}$ in the HBOT and control group, respectively [104]. These patients received salvage HBOT therapy till 20 weeks after initial hearing loss. Sun et al. did not find any differences between the control, intratympanic dexamethasone and HBOT groups in the salvage treatment of ISSHL [139]. Horn et al. performed a prospective trial with HBOT in nine ISSHL patients who failed steroid and antiviral treatment. They started HBOT after an average of 5.8 weeks, and did not find any significant results [85].

Yang et al. found positive results of salvage combination therapy with HBOT and intratympanic corticosteroids. They reported good recovery in $68.4 \%$ of all patients treated with the salvage combination therapy, compared to salvage intratympanic corticosteroid monotherapy (48.6\%), salvage 
HBO monotherapy (54.5\%) and no salvage therapy (22.2\%); the results were statistically significant $(P=0.018)$. Salvage therapy in this study was quickly initiated after failure of primary therapy. The combination therapy was initiated after 5 days from onset of hearing loss. Therefore, patients in this study were still in the theoretical plausible effective time frame of HBOT initiation [108].

Grounded on the theoretical foundation of HBOT and combined with these results, it is clear that the utilization of HBOT as salvage therapy is not the most effective option. HBOT is most likely to have good effects when it is used early after onset of symptoms, because it could prevent further ischemia within the inner ear in the time frame that the inner ear suffers most hypoxia.

\section{Other therapies}

Due to the proposed vascular etiology, many other treatment modalities were proposed and experimentally tested. Examples of treatments are blood flow-promoting agents, vasodilators, diuretics, dextran and pentoxifylline. However, many of those studies (Chi, Liu, Ohno, Satar, Narozny, Aslan, Topuz, Racic) have failed to show effectiveness in the clinical setting [81-84, 91, 104, 105, 121].

\section{Recovery in recent systematic reviews}

In 2014, van der Veen et al. published a review on the effectiveness of HBOT in AAT. Due to the small amount of studies and poor methodology of the studies, it was concluded that it was unclear what the clinical effect is of HBOT in AAT [140].

In ISSHL, spontaneous recovery ranges between 25 and $39 \%$ and most commonly occurs within the first $24 \mathrm{~h}$ [141]. In 2012, Bennet et al. published a Cochrane review, in which they proposed that HBOT may work for ISSHL but, due to the very low amount of studies (Topuz, Fattori, Schwab, Cavallazzi, Hoffmann, Pilgramm) [83, 101, 133, 142-144] with small patient sizes and poor methodology, it was not possible to draw strong conclusions. They reported that the mean difference in hearing gain between HBOT and control treatment was $15.6 \mathrm{~dB}(P=0.039)$. Furthermore, they found that the recovery ( $>25 \%$ return of hearing level) was in favor of HBOT [RR 1.39 (1.05-1.84), $P=0.022$ ] [145].

More recently, Rhee et al. performed a meta-analysis on the complete recovery in HBOT and medical therapy (MT) patients. They found that in 14 studies, HBOT had significantly higher complete recovery $(29.4 \%$ vs $20.6 \%, P=0.03)$ compared to MT patients. However, it must be noted that the definition of complete recovery varied from study to study. Even though great heterogeneity exists between the definition of 'complete recovery' in different studies, HBOT was superior to MT in terms of complete recovery in the majority of studies (12 out of 14) [146]. Other authors (Eryigit, Saesen, Murphy-Lavoie) have also published reviews on the use of HBOT in ISSHL [27, 147, 148]. Their conclusions were mostly positive, especially showing results in favor of HBOT in patients with severe and profound hearing loss.

\section{Hyperbaric oxygen therapy}

HBOT is a relatively time-consuming therapy for patients due to the fact that patients must be physically present in the oxygen chamber for $90 \mathrm{~min}$ in at least 10 days. Therefore, Attanasio et al. investigated whether addition of a second daily session of HBOT influenced the outcomes of treatment in ISSHL. They found no significant difference between one and two daily sessions; therefore, two daily sessions may be used for patients suffering from ISSHL [111]. This may improve therapy adherence and reduce the patients' burden of therapy. HBOT is considered a safe therapy; however, side effects do occur in some studies. Most often side effects consist of barotrauma to middle ear and sinus [149]. Fujimura et al. reported side effects in 17 of the 67 patients $(25.4 \%)$. Of these 17 patients, 9 developed otitis media with effusion, for which myringotomy was required in 4 cases, and 1 patient underwent tympanostomy tube insertion [88].

\section{No effect or negative results after HBOT}

Gülüstan et al. found no significant difference between HBOT and ITS when compared to each other. This study only took into account both therapies as individual entities and did not combine both treatments as proposed in the rationale for therapy [116].

Tasdöven et al. reported higher levels of complete recovery in the group of patients who were treated with oral corticosteroids only compared to a group with combined oral corticosteroids and HBOT and another group consisting of oral corticosteroids and ozone therapy. However, the responses to therapy (hearing gain $>15 \mathrm{~dB}$ ) was higher in the ozone and HBOT groups (82.4 and 61.5\%) compared to the only corticosteroids group (50.8\%) [150]. It was unclear what the time difference was from the onset of symptoms and initiation of therapy.

Almosnino et al. found no difference between the combination HBOT and ITS vs ITS in patients who failed on conventional steroid therapy. The reason for not finding a difference may be due to the late initiation of HBOT (29.1 days) [122]. 


\section{Recommendations}

For future studies, we recommend starting therapy as early as possible, preferably within $48 \mathrm{~h}$ and to use combination therapy consisting of HBOT and corticosteroids. Furthermore, we recommend the use of standardized outcomes with absolute and relative hearing gains, especially in the affected frequencies and to collect speech recognition outcomes. For clinical recovery we refer to the guidelines of the American Academy [151].

\section{Conclusion}

HBOT has been used quite extensively for acute hearing loss in the last couple of decades. This narrative review has described the rationale and clinical evidence for early initiation of HBOT combined with corticosteroids for, especially severe, acute hearing loss. Even though most studies were not randomized controlled trials, we think that based on the number of of studies showing a positive effect, HBOT should be discussed with patients (shared decision making) as optional therapy in case of AAT and ISSHL.

\section{Compliance with ethical standards}

Conflict of interest The authors declare that they have no conflict of interest.

Human and animal rights This article does not contain any studies with human participants or animals performed by any of the authors.

Open Access This article is distributed under the terms of the Creative Commons Attribution 4.0 International License (http://creativeco mmons.org/licenses/by/4.0/), which permits unrestricted use, distribution, and reproduction in any medium, provided you give appropriate credit to the original author(s) and the source, provide a link to the Creative Commons license, and indicate if changes were made.

\section{References}

1. Plontke SK, Meisner C, Caye-Thomasen P, Parnes L, Agrawal S, Mikulec T (2009) Intratympanic glucocorticoids for sudden sensorineural hearing loss. Cochrane Database Syst Rev 4:4

2. Rauch SD (2008) Clinical practice. Idiopathic sudden sensorineural hearing loss. N Engl J Med 359(8):833-840

3. Helfer TM, Canham-Chervak M, Canada S, Mitchener TA (2010) Epidemiology of hearing impairment and noise-induced hearing injury among US military personnel, 2003-2005. Am J Prevent Med 38(1 Suppl):S71-S77

4. Alexander TH, Harris JP (2013) Incidence of sudden sensorineural hearing loss. Otol Neurotol 34(9):1586-1589
5. Yong JS, Wang DY (2015) Impact of noise on hearing in the military. Military Med Res 2:6

6. Stachler RJ, Chandrasekhar SS, Archer SM et al (2012) Clinical practice guideline: sudden hearing loss. Otolaryngol Head Neck Surg 146(3 Suppl):S1-S35

7. Ryan AF, Kujawa SG, Hammill T, Le Prell C, Kil J (2016) Temporary and permanent noise-induced threshold shifts: a review of basic and clinical observations. Otol Neurotol 37(8):e271-e275

8. Tabuchi K, Nishimura B, Tanaka S, Hayashi K, Hirose Y, Hara A (2010) Ischemia-reperfusion injury of the cochlea: pharmacological strategies for cochlear protection and implications of glutamate and reactive oxygen species. Curr Neuropharmacol $8(2): 128-134$

9. Shi X (2011) Physiopathology of the cochlear microcirculation. Hear Res 282(1-2):10-24

10. Misrahy GA, Shinabarger EW, Arnold JE (1958) Changes in cochlear endolymphatic oxygen availability, action potential, and microphonics during and following asphyxia, hypoxia, and exposure to loud sounds. J Acoust Soc Am 30(8):701-704

11. Hillerdal M, Jansson B, Engstrom B, Hultcrantz E, Borg E (1987) Cochlear blood flow in noise-damaged ears. Acta Otolaryngol 104(3-4):270-278

12. Lamm K, Arnold W (1999) Successful treatment of noiseinduced cochlear ischemia, hypoxia, and hearing loss. Ann N Y Acad Sci 884:233-248

13. Quirk WS, Avinash G, Nuttall AL, Miller JM (1992) The influence of loud sound on red blood cell velocity and blood vessel diameter in the cochlea. Hear Res 63(1-2):102-107

14. Scheibe F, Haupt H, Ludwig C (1993) Intensity-related changes in cochlear blood flow in the guinea pig during and following acoustic exposure. Eur Arch Oto-Rhino-Laryngol 250(5):281-285

15. Seidman MD, Quirk WS, Shirwany NA (1999) Mechanisms of alterations in the microcirculation of the cochlea. Ann N Y Acad Sci 884:226-232

16. Yamane H, Nakai Y, Konishi K, Sakamoto H, Matsuda Y, Iguchi H (1991) Strial circulation impairment due to acoustic trauma. Acta Otolaryngol 111(1):85-93

17. Ruben RJ, Distenfeld A, Berg P, Carr R (1969) Sudden sequential deafness as the presenting symptom of macroglobulinemia. JAMA 209(9):1364-1365

18. Sone M, Mizuno T, Naganawa S, Nakashima T (2009) Imaging analysis in cases with inflammation-induced sensorineural hearing loss. Acta Otolaryngol 129(3):239-243

19. Chang SL, Hsieh CC, Tseng KS, Weng SF, Lin YS (2014) Hypercholesterolemia is correlated with an increased risk of idiopathic sudden sensorineural hearing loss: a historical prospective cohort study. Ear Hear 35(2):256-261

20. Rudack C, Langer C, Stoll W, Rust S, Walter M (2006) Vascular risk factors in sudden hearing loss. Thromb Haemost 95(3):454-461

21. Morgenstein KM, Manace ED (1969) Temporal bone histopathology in sickle cell disease. Laryngoscope 79(12):2172-2180

22. Gussen R (1976) Sudden deafness of vascular origin: a human temporal bone study. Ann Otol Rhinol Laryngol 85(1 Pt 1):94-100

23. Fisch U, Nagahara K, Pollak A (1984) Sudden hearing loss: circulatory. Am J Otol 5(6):488-491

24. Elwany S, Kamel T (1988) Sensorineural hearing loss in sickle cell crisis. Laryngoscope 98(4):386-389

25. Agarwal L, Pothier DD (2009) Vasodilators and vasoactive substances for idiopathic sudden sensorineural hearing loss. Cochrane Database Syst Rev (4)

26. Boerema I, Huiskes JW, Kroll JA, Kroon B, Lokin E, Meyne NG (1956) High atmospheric pressure as an aid to cardiac surgery. Archivum Chirurgicum Neerlandicum 8(3):193-211 
27. Eryigit B, Ziylan F, Yaz F, Thomeer H (2018) The effectiveness of hyperbaric oxygen in patients with idiopathic sudden sensorineural hearing loss: a systematic review. Eur Arch Oto-RhinoLaryngol 275(12):2893-2904

28. Kusakari J, Kambayashi J, Kobayashi T et al (1981) The effect of transient anoxia upon the cochlear potentials. Auris Nasus Larynx 8(2):55-64

29. Offner FF, Dallos P, Cheatham MA (1987) Positive endocochlear potential: mechanism of production by marginal cells of stria vascularis. Hear Res 29(2-3):117-124

30. Lamm K, Lamm C, Lamm H, Schumann K (1988) Simultaneous determinations of oxygen partial pressure in the scala tympani, electrocochleography and blood pressure measurements in noise stress in guinea pigs. HNO 36(9):367-372

31. Scheibe F, Haupt H, Ludwig C (1992) Intensity-dependent changes in oxygenation of cochlear perilymph during acoustic exposure. Hear Res 63(1-2):19-25

32. Fisch U (1983) Management of sudden deafness. Otolaryngol Head Neck Surg 91(1):3-8

33. Hawkins JE Jr (1971) The role of vasoconstriction in noiseinduced hearing loss. Ann Otol Rhinol Laryngol 80(6):903-913

34. Hawkins JE Jr, Johnsson LG, Preston RE (1972) Cochlear microvasculature in normal and damaged ears. Laryngoscope 82(7):1091-1104

35. Lipscomb DM, Roettger RL (1973) Capillary constriction in cochlear and vestibular tissues during intense noise stimulation. Laryngoscope 83(2):259-263

36. Vertes D, Axelsson A, Lipscomb DM (1979) Some vascular effects of noise exposure in the chinchilla cochlea. Arch OtoRhino-Laryngol 224(1-2):97-101

37. Vertes D, Axelsson A (1981) Cochlear vascular histology in animals exposed to noise. Arch Oto-Rhino-Laryngol 230(3):285-288

38. Axelsson A, Dengerink H (1981) The effects of noise on histological measures of the cochlear vasculature and red blood cells: a review. Hearing res 31(2):183-191

39. Shaddock LC, Hamernik RP, Axelsson A (1985) Effect of high intensity impulse noise on the vascular system of the chinchilla cochlea. Ann Otol Rhinol Laryngol 94(1 Pt 1):87-92

40. Dengerink H, Miller J, Axelsson A, Vertes D, Van Dalfsen P (1985) The recovery of vascular changes following brief noise exposure. Acta Otolaryngol 100(1-2):19-25

41. Axelsson A, Dengerink H (1987) The effects of noise on histological measures of the cochlear vasculature and red blood cells: a review. Hear Res 31(2):183-191

42. Lamm H, Lamm K, Zimmermann W (1982) The effects of hyperbaric oxygen on experimental noise damage to the ears. Arch Oto-Rhino-Laryngol 236(3):237-244

43. Hu ZY, Shi XF, Liang ZF, Tang ZW, Jin XQ (1991) The protective effect of hyperbaric oxygen on hearing during chronic noise exposure. Aviat Space Environ Med 62(5):403-406

44. Tilney LG, Saunders JC, Egelman E, DeRosier DJ (1982) Changes in the organization of actin filaments in the stereocilia of noise-damaged lizard cochleae. Hear Res 7(2):181-197

45. Avinash GB, Nuttall AL, Raphael Y (1993) 3-D analysis of F-actin in stereocilia of cochlear hair cells after loud noise exposure. Hear Res 67(1-2):139-146

46. Liberman MC, Beil DG (1979) Hair cell condition and auditory nerve response in normal and noise-damaged cochleas. Acta Otolaryngol 88(3-4):161-176

47. Pilgramm M (1991) Clinical and animal experiment studies to optimise the therapy for acute acoustic trauma. Scand Audiol Suppl 34:103-122

48. Kuokkanen J, Aarnisalo AA, Ylikoski J (2000) Efficiency of hyperbaric oxygen therapy in experimental acute acoustic trauma from firearms. Acta Oto-Laryngol Suppl 543:132-134
49. Kuokkanen J, Virkkala J, Zhai S, Ylikoski J (1997) Effect of hyperbaric oxygen treatment on permanent threshold shift in acoustic trauma among rats. Acta Oto Laryngol Suppl 529:80-82

50. Colombari GC, Rossato M, Feres O, Hyppolito MA (2011) Effects of hyperbaric oxygen treatment on auditory hair cells after acute noise damage. Eur Arch Oto-Rhino-Laryngol 268(1):49-56

51. Yamane H, Nakai Y, Takayama M, Iguchi H, Nakagawa T, Kojima A (1995) Appearance of free radicals in the guinea pig inner ear after noise-induced acoustic trauma. Eur Arch Oto Rhino Laryngol 252(8):504-508

52. Ohlemiller KK, Wright JS, Dugan LL (1999) Early elevation of cochlear reactive oxygen species following noise exposure. Audiolo Neuro-otol 4(5):229-236

53. Morrow JD, Roberts LJ 2nd (1996) The isoprostanes. Current knowledge and directions for future research. Biochem Pharmacol 51(1):1-9

54. Ohinata Y, Miller JM, Altschuler RA, Schacht J (2000) Intense noise induces formation of vasoactive lipid peroxidation products in the cochlea. Brain Res 878(1-2):163-173

55. Wakabayashi K, Fujioka M, Kanzaki S et al (2010) Blockade of interleukin-6 signaling suppressed cochlear inflammatory response and improved hearing impairment in noise-damaged mice cochlea. Neurosci Res 66(4):345-352

56. Keithley EM, Wang X, Barkdull GC (2008) Tumor necrosis factor alpha can induce recruitment of inflammatory cells to the cochlea. Otol Neurotol 29(6):854-859

57. Tan WJ, Thorne PR, Vlajkovic SM (2016) Characterisation of cochlear inflammation in mice following acute and chronic noise exposure. Histochem Cell Biol 146(2):219-230

58. Lo YY, Wong JM, Cruz TF (1996) Reactive oxygen species mediate cytokine activation of c-Jun NH2-terminal kinases. J Biol Chem 271(26):15703-15707

59. Wang J, Ruel J, Ladrech S, Bonny C, van de Water TR, Puel JL (2007) Inhibition of the c-Jun N-terminal kinase-mediated mitochondrial cell death pathway restores auditory function in sound-exposed animals. Mol Pharmacol 71(3):654-666

60. Han W, Shi X, Nuttall AL (2006) AIF and endoG translocation in noise exposure induced hair cell death. Hear Res 211(1-2):85-95

61. Arslan HH, Satar B, Serdar MA, Ozler M, Yilmaz E (2012) Effects of hyperbaric oxygen and dexamethasone on proinflammatory cytokines of rat cochlea in noise-induced hearing loss. Otol Neurotol 33(9):1672-1678

62. Kahraman E, Ata N, Incesulu A, Bal C (2012) The role of different agents in the prevention of the negative effects of immediate hyperbaric oxygen therapy in acute acoustic trauma. J Int Adv Otology 8(2):158-165

63. Hamernik RP, Turrentine G, Roberto M, Salvi R, Henderson D (1984) Anatomical correlates of impulse noise-induced mechanical damage in the cochlea. Hear Res 13(3):229-247

64. Yamashita D, Jiang HY, Schacht J, Miller JM (2004) Delayed production of free radicals following noise exposure. Brain Res 1019(1-2):201-209

65. Takemura K, Komeda M, Yagi M et al (2004) Direct inner ear infusion of dexamethasone attenuates noise-induced trauma in guinea pig. Hear Res 196(1-2):58-68

66. Kurabi A, Keithley EM, Housley GD, Ryan AF, Wong AC (2017) Cellular mechanisms of noise-induced hearing loss. Hear Res 349:129-137

67. Wong AC, Ryan AF (2015) Mechanisms of sensorineural cell damage, death and survival in the cochlea. Front Aging Neurosci 7:58

68. Henderson D, Bielefeld EC, Harris KC, Hu BH (2006) The role of oxidative stress in noise-induced hearing loss. Ear Hear 27(1):1-19 
69. Appaix A, Pech A, Demard F (1970) The use of hyperbaric oxygen in oto-rhino-laryngology. Annales d'oto-laryngologie et de chirurgie cervico faciale: bulletin de la Societe d'otolaryngologie des hopitaux de Paris 87(12):735-750

70. Lamm H, Klimpel L (1971) Hyperbaric oxygen therapy in internal ear and vestibular disorders: preliminary report. Hno 19(12):363-369

71. De Heyn G, Van Opstal M (1976) Comparative study of acoustic trauma caused by blasts, treated by vasodilators or by a combination of vasodilators and hyperbaric oxygenation. Acta Otorhinolaryngol Belg 30(3):251-259

72. Vincey P (1978) Application and use of hyperbaric oxygenation in ENT. Revue de Laryngologie-Otologie-Rhinologie 99(9-10):619-634

73. Goto F, Fujita T, Kitani Y, Kanno M, Kamei T, Ishii H (1979) Hyperbaric oxygen and stellate ganglion blocks for idiopathic sudden hearing loss. Acta Otolaryngol 88(5-6):335-342

74. Demaertelaere L, Van Opstal M (1981) Treatment of acoustic trauma with hyperbaric oxygen. Acta Otorhinolaryngol Belg 35(3-4):303-314

75. Vavrina J, Muller W (1995) Therapeutic effect of hyperbaric oxygenation in acute acoustic trauma. Revue de LaryngologieOtologie-Rhinologie 116(5):377-380

76. Pilgramm M, Schumann K (1985) Hyperbaric oxygen therapy for acute acoustic trauma. Arch Oto-Rhino-Laryngol 241(3):247-257

77. Winiarski M, Kantor I, Smereka J, Jurkiewicz D (2005) Effectiveness of pharmacologic therapy combined with hyperbaric oxygen in sensorineural hearing loss following acute acoustic trauma: preliminary report. Polski merkuriusz lekarski: organ Polskiego Towarzystwa Lekarskiego 19(111):348-350

78. Ylikoski J, Mrena R, Makitie A, Kuokkanen J, Pirvola U, Savolainen S (2008) Hyperbaric oxygen therapy seems to enhance recovery from acute acoustic trauma. Acta Otolaryngol 128(10):1110-1115

79. Lamm K, Lamm H, Arnold W (1998) Effect of hyperbaric oxygen therapy in comparison to conventional or placebo therapy or no treatment in idiopathic sudden hearing loss, acoustic trauma, noise-induced hearing loss and tinnitus. A literature survey. Adv Oto-Rhino-Laryngol 54:86-99

80. Nakashima T, Fukuta S, Yanagita N (1998) Hyperbaric oxygen therapy for sudden deafness. Adv Otorhinolaryngol 54:100-109

81. Aslan I, Oysu C, Veyseller B, Baserer N (2002) Does the addition of hyperbaric oxygen therapy to the conventional treatment modalities influence the outcome of sudden deafness? Otolaryngol Head Neck Surg 126(2):121-126

82. Racic G, Maslovara S, Roje Z, Dogas Z, Tafra R (2003) Hyperbaric oxygen in the treatment of sudden hearing loss. ORL 65(6):317-320

83. Topuz E, Yigit O, Cinar U, Seven H (2004) Should hyperbaric oxygen be added to treatment in idiopathic sudden sensorineural hearing loss? Eur Arch Oto Rhino Laryngol 261(7):393-396

84. Narozny W, Sicko Z, Przewozny T, Stankiewicz C, Kot J, Kuczkowski J (2004) Usefulness of high doses of glucocorticoids and hyperbaric oxygen therapy in sudden sensorineural hearing loss treatment. Otol Neurotol 25(6):916-923

85. Horn CE, Himel HN, Selesnick SH (2005) Hyperbaric oxygen therapy for sudden sensorineural hearing loss: a prospective trial of patients failing steroid and antiviral treatment. Otol Neurotol 26(5):882-889

86. Desloovere C, Knecht R, Germonpre P (2006) Hyperbaric oxygen therapy after failure of conventional therapy for sudden deafness. B-ENT 2(2):69-73
87. Dundar K, Gumus T, Ay H, Yetiser S, Ertugrul E (2007) Effectiveness of hyperbaric oxygen on sudden sensorineural hearing loss: prospective clinical research. J Otolaryngol 36(1):32-37

88. Fujimura T, Suzuki H, Shiomori T, Udaka T, Mori T (2007) Hyperbaric oxygen and steroid therapy for idiopathic sudden sensorineural hearing loss. Eur Arch Oto Rhino Laryngol 264(8):861-866

89. Muzzi E, Zennaro B, Visentin R, Soldano F, Sacilotto C (2010) Hyperbaric oxygen therapy as salvage treatment for sudden sensorineural hearing loss: review of rationale and preliminary report. J Laryngol Otol 124(2):e2

90. Kestler M, Strutz J, Heiden C (2001) Hyperbaric oxygenation in early treatment of sudden deafness. Hno 49(9):719-723

91. Satar B, Hidir Y, Yetiser S (2006) Effectiveness of hyperbaric oxygen therapy in idiopathic sudden hearing loss. J Laryngol Otol 120(8):665-669

92. Lopez-Gonzalez MA, Abrante A, Lopez-Lorente C, Gomez A, Dominguez E, Esteban F (2012) Acute-phase inflammatory response in idiopathic sudden deafness: pathogenic implications. Int J Otolaryngol 2012:216592

93. Kalinec GM, Lomberk G, Urrutia RA, Kalinec F (2017) Resolution of cochlear inflammation: novel target for preventing or ameliorating drug-, noise- and age-related hearing loss. Front Cell Neurosci 11:192

94. Wilson WR, Byl FM, Laird N (1980) The efficacy of steroids in the treatment of idiopathic sudden hearing loss: a double-blind clinical study. Arch Otolaryngol 106(12):772-776

95. McMahon M, Gerich J, Rizza R (1988) Effects of glucocorticoids on carbohydrate metabolism. Diabetes Metab Rev 4(1):17-30

96. Lamm K, Arnold W (1996) Noise-induced cochlear hypoxia is intensity dependent, correlates with hearing loss and precedes reduction of cochlear blood flow. Audiol Neuro-otol 1(3): $148-160$

97. d'Aldin C, Cherny L, Devriere F, Dancer A (1999) Treatment of acoustic trauma. Ann N Y Acad Sci 884:328-344

98. Fakhry N, Rostain JC, Cazals Y (2007) Hyperbaric oxygenation with corticoid in experimental acoustic trauma. Hear Res 230(1-2):88-92

99. Alimoglu Y, Inci E, Edizer DT, Ozdilek A, Aslan M (2011) Efficacy comparison of oral steroid, intratympanic steroid, hyperbaric oxygen and oral steroid + hyperbaric oxygen treatments in idiopathic sudden sensorineural hearing loss cases. Eur Arch Oto-Rhino-Laryngol 268(12):1735-1741

100. Capuano L, Cavaliere M, Parente G et al (2015) Hyperbaric oxygen for idiopathic sudden hearing loss: is the routine application helpful? Acta Otolaryngol 135(7):692-697

101. Cavallazzi G, Pignataro L, Capaccio P (1996) Italian experience in hyperbaric oxygen therapy for idiopathic sudden sensorineural hearing loss. Int Joint Meet Hyperb Underw Med 1996:5-8

102. Cekin E, Cincik H, Ulubil SA, Gungor A (2009) Effectiveness of hyperbaric oxygen therapy in management of sudden hearing loss. J Laryngol Otol 123(6):609-612

103. Lafere P, Vanhoutte D, Germonpre P (2010) Hyperbaric oxygen therapy for acute noise-induced hearing loss: evaluation of different treatment regimens. Diving Hyperb Med 40(2):63-67

104. Ohno K, Noguchi Y, Kawashima Y, Yagishita K, Kitamura K (2010) Secondary hyperbaric oxygen therapy for idiopathic sudden sensorineural hearing loss in the subacute and chronic phases. J Med Dent Sci 57(2):127-132

105. Liu SC, Kang BH, Lee JC et al (2011) Comparison of therapeutic results in sudden sensorineural hearing loss with/without additional hyperbaric oxygen therapy: a retrospective review of 465 audiologically controlled cases. Clin Otolaryngol 36(2):121-128

106. Imsuwansri T, Poonsap P, Snidvongs K (2012) Hyperbaric oxygen therapy for sudden sensorineural hearing loss after failure 
from oral and intratympanic corticosteroid. Clin Exp Otorhinolaryngol 5(Suppl 1):S99-s102

107. Suzuki H, Hashida K, Nguyen KH et al (2012) Efficacy of intratympanic steroid administration on idiopathic sudden sensorineural hearing loss in comparison with hyperbaric oxygen therapy. Laryngoscope 122(5):1154-1157

108. Yang $\mathrm{CH}$, Wu RW, Hwang CF (2013) Comparison of intratympanic steroid injection, hyperbaric oxygen and combination therapy in refractory sudden sensorineural hearing loss. Otol Neurotol 34(8):1411-1416

109. Bonfort G, Billot D, Trendel D, Salf E, Lindas P, Barberot JP (2014) Acute acoustic trauma, a retrospective analysis about 225 military cases. Revue de laryngologie-otologie-rhinologie 135(1):25-31

110. Yildirim E, Murat Ozcan K, Palali M, Cetin MA, Ensari S, Dere H (2015) Prognostic effect of hyperbaric oxygen therapy starting time for sudden sensorineural hearing loss. Eur Arch Oto-RhinoLaryngol 272(1):23-28

111. Attanasio G, Covelli E, Cagnoni L et al (2015) Does the addition of a second daily session of hyperbaric oxygen therapy to intratympanic steroid influence the outcomes of sudden hearing loss? Acta otorhinolaryngologica Italica: organo ufficiale della Societa italiana di otorinolaringologia e chirurgia cervico-facciale 35(4):272-276

112. Naibogllu B, Kulekci S, Surmeli M et al (2015) Efficacy of multimodality approach to sudden hearing loss. J Ear Nose Throat 25(2):77-81

113. Edizer DT, Celebi O, Hamit B, Baki A, Yigit O (2015) Recovery of Idiopathic Sudden Sensorineural Hearing Loss. J Int Adv Otol 11(2):122-126

114. Pezzoli M, Magnano M, Maffi L et al (2015) Hyperbaric oxygen therapy as salvage treatment for sudden sensorineural hearing loss: a prospective controlled study. Eur Arch Oto-Rhino-Laryngol 272(7):1659-1666

115. Psillas G, Ouzounidou S, Stefanidou S et al (2015) Hyperbaric oxygen as salvage treatment for idiopathic sudden sensorineural hearing loss. B-ENT 11(1):39-44

116. Gulustan F, Yazici ZM, Alakhras WME et al (2016) Intratympanic steroid injection and hyperbaric oxygen therapy for the treatment of refractory sudden hearing loss. Braz J Otorhinolaryngol 84:1808-8694

117. Akil F, Yollu U, Yilmaz M, Yener HM, Mamanov M, Inci E (2017) Simultaneous idiopathic bilateral sudden hearing losscharacteristics and response to treatment. Braz J Otorhinolaryngol 84(1):95-101

118. Ricciardiello F, Abate T, Pianese A et al (2017) Sudden sensorineural hearing loss: role of hyperbaric oxygen therapy. Transl Med Rep 1(1):13-16

119. Van Haesendonck G, Van Rompaey V, Gilles A, Topsakal V, Van de Heyning P (2018) Otologic outcomes after blast injury: the brussels bombing experience. Otol Neurotol 39(10):1250-1255

120. Xie S, Qiang Q, Mei L et al (2018) Multivariate analysis of prognostic factors for idiopathic sudden sensorineural hearing loss treated with adjuvant hyperbaric oxygen therapy. Eur Arch OtoRhino-Laryngol 275(1):47-51

121. Chi TH, Chiang MC, Chen RF, Yuan CH (2018) Does the addition of hyperbaric oxygen therapy to conventional treatment modalities influence the outcome of soldiers with idiopathic sudden sensorineural hearing loss? J R Army Med Corps 164(2):69-71

122. Almosnino G, Holm JR, Schwartz SR, Zeitler DM (2018) The role of hyperbaric oxygen as salvage therapy for sudden sensorineural hearing loss. Ann Otol Rhinol Laryngol 127(10):672-676

123. Krajcovicova Z, Melus V, Zigo R, Matisakova I, Vecera J, Kaslikova K (2018) Efficacy of hyperbaric oxygen therapy as a supplementary therapy of sudden sensorineural hearing loss in the Slovak Republic. Undersea Hyperb Med J Undersea Hyperb Med Soc 45(3):363-370

124. Cho I, Lee HM, Choi SW et al (2018) Comparison of two different treatment protocols using systemic and intratympanic steroids with and without hyperbaric oxygen therapy in patients with severe to profound idiopathic sudden sensorineural hearing loss: a randomized controlled trial. Audiol Neuro-otol 23(4):199-207

125. Khater A, El-Anwar MW, Nofal AA, Elbahrawy AT (2018) Sudden sensorineural hearing loss: comparative study of different treatment modalities. Int Arch Otorhinolaryngol 22(3):245-249

126. Bayoumy AB, van der Veen EL, van Ooij PAM et al (2019) Effect of hyperbaric oxygen therapy and corticosteroid therapy in military personnel with acute acoustic trauma. J R Army Med Corps. https://doi.org/10.1136/jramc-2018-001117

127. Hosokawa S, Hosokawa K, Takahashi G et al (2018) Hyperbaric oxygen therapy as concurrent treatment with systemic steroids for idiopathic sudden sensorineural hearing loss: a comparison of three different steroid treatments. Audiol Neuro-otol 23(3):145-151

128. Filipo R, Attanasio G, Russo FY, Viccaro M, Mancini P, Covelli E (2013) Intratympanic steroid therapy in moderate sudden hearing loss: a randomized, triple-blind, placebo-controlled trial. Laryngoscope 123(3):774-778

129. Salihoglu M, Ay H, Cincik H et al (2015) Efficiency of hyperbaric oxygen and steroid therapy in treatment of hearing loss following acoustic trauma. Undersea Hyperb Med J Undersea Hyperb Med Soc 42(6):539-546

130. Holy R, Navara M, Dosel P, Fundova P, Prazenica P, Hahn A (2011) Hyperbaric oxygen therapy in idiopathic sudden sensorineural hearing loss (ISSNHL) in association with combined treatment. Undersea Hyperb Med J Undersea Hyperb Med Soc 38(2):137-142

131. Hosokawa S, Sugiyama K, Takahashi G, Takebayashi S, Mineta $\mathrm{H}$ (2017) Prognostic factors for idiopathic sudden sensorineural hearing loss treated with hyperbaric oxygen therapy and intravenous steroids. J Laryngol Otol 131(1):77-82

132. Karatop-Cesur I, Uzun G, Ozgok-Kangal K, Mutluoglu M, Yildiz S (2016) Early treatment response predicts outcome in patients with idiopathic sudden sensorineural hearing loss treated with hyperbaric oxygen therapy. Undersea Hyperb Med J Undersea Hyperb Med Soc 43(7):781-786

133. Fattori B, Berrettini S, Casani A, Nacci A, De Vito A, De Iaco G (2001) Sudden hypoacusis treated with hyperbaric oxygen therapy: a controlled study. Ear Nose Throat J 80(9):655-660

134. Ajduk J, Ries M, Trotic R, Marinac I, Vlatka K, Bedekovic V (2017) Hyperbaric oxygen therapy as salvage therapy for sudden sensorineural hearing loss. J Int Adv Otol 13(1):61-64

135. Sherlock S, Thistlethwaite K, Khatun M, Perry C, Tabah A (2016) Hyperbaric oxygen therapy in the treatment of sudden sensorineural hearing loss: a retrospective analysis of outcomes. Diving Hyperb Med 46(3):160-165

136. Plontke SK, Bauer M, Meisner C (2007) Comparison of puretone audiometry analysis in sudden hearing loss studies: lack of agreement for different outcome measures. Otol Neurotol 28(6):753-763

137. Cvorovic L, Jovanovic MB, Milutinovic Z, Arsovic N, Djeric D (2013) Randomized prospective trial of hyperbaric oxygen therapy and intratympanic steroid injection as salvage treatment of sudden sensorineural hearing loss. Otol Neurotol 34(6):1021-1026

138. Hosokawa S, Sugiyama KI, Takahashi G et al (2017) Hyperbaric oxygen therapy as adjuvant treatment for idiopathic sudden sensorineural hearing loss after failure of systemic steroids. Audiol Neuro-otol 22(1):9-14 
139. Sun H, Qiu X, Hu J, Ma Z (2018) Comparison of intratympanic dexamethasone therapy and hyperbaric oxygen therapy for the salvage treatment of refractory high-frequency sudden sensorineural hearing loss. Am J Otolaryngol 39(5):531-535

140. van der Veen EL, van Hulst RA, de Ru JA (2014) Hyperbaric oxygen therapy in acute acoustic trauma: a rapid systematic review. Otolaryngol Head Neck Surg 151(1):42-45

141. Bayoumy AB, van der Veen EL, Alexander de Ru J (2018) Assessment of spontaneous recovery rates in patients with idiopathic sudden sensorineural hearing loss. JAMA otolaryngol Head Neck Surg 144(8):655-656

142. Schwab B, Flunkert C, Heermann R, Lenarz T (1998) HBO in the therapy of cochlear dysfunctions: first results of a randomized study. EUBS Diving and Hyperbaric Medicine, Collected Manuscripts of XXIV Annual Scientific Meeting of the European Underwater and Baromedical Society

143. Hoffman G, Bohmar D, Desloovere C (1995) Hyperbaric oxygenation as a treatment of chronic forms of inner ear hearing loss and tinnitus. Proc Eleventh Int Congr Hyperb Med 1995:141-145

144. Pilgramm M, Lamm H, Schumann K (1985) Hyperbaric oxygen therapy in sudden deafness. Laryngologie Rhinologie Otologie 64(7):351-354

145. Bennett MH, Kertesz T, Perleth M, Yeung P, Lehm JP (2012) Hyperbaric oxygen for idiopathic sudden sensorineural hearing loss and tinnitus. Cochrane Datab Syst Rev 10:Cd004739

146. Rhee TM, Hwang D, Lee JS, Park J, Lee JM (2018) Addition of hyperbaric oxygen therapy vs medical therapy alone for idiopathic sudden sensorineural hearing loss: a systematic review and meta-analysis. JAMA Otolaryngol Head Neck Surg 144(12): 1153-1161

147. Saesen K, Loos E, Montagna C, Vanbrabant T, Goedhuys R, Lemkens N (2017) Hyperbaric oxygen therapy in idiopathic sudden sensorineural hearing loss. B-ent 13(2):105-112

148. Murphy-Lavoie H, Piper S, Moon RE, Legros T (2012) Hyperbaric oxygen therapy for idiopathic sudden sensorineural hearing loss. Undersea Hyperb Med J Undersea Hyperb Med Soc 39(3):777-792

149. Plafki C, Peters P, Almeling M, Welslau W, Busch R (2000) Complications and side effects of hyperbaric oxygen therapy. Aviat Space Environ Med 71(2):119-124

150. Ergun Tasdoven G, Derin AT, Yaprak N, Ozcaglar HU (2017) The place of hyperbaric oxygen therapy and ozone therapy in sudden hearing loss. Braz J Otorhinolaryngol 83(4):457-463

151. (1995) Committee on Hearing and Equilibrium guidelines for the evaluation of hearing preservation in acoustic neuroma (vestibular schwannoma). American academy of otolaryngologyhead and neck surgery foundation, Inc. Otolaryngol Head Neck Surg 113(3): 179-180

152. Lamm H, Muller-Kortkamp C, Warnecke A et al (2016) Concurrent hyperbaric oxygen therapy and intratympanic steroid application as salvage therapy after severe sudden sensorineural hearing loss. Clin Case Rep 4(3): 287-293

153. Van Der Wal AW, Van Ooij PJ, De Ru JA (2016) Hyperbaric oxygen therapy for sudden sensorineural hearing loss in divers. J laryngol otol 130(11):1039-1047

154. Živaljević Z, Zivic L, Mihailovic N, Zivkovic M, Vorkapic B, Baletic N (2017) Treatment of sudden sensorineural hearing loss with hyperbaric oxygenation-our experience. Vojnosanit Pregl 74(2):156-160

155. Guha D, Sanyal S, Bhattacharyya C, Santra A, Banerjee S (2015) Hyperbaric oxygen therapy in the treatment of idiopathic sudden sensorineural hearing loss. Bengal J Otolaryngol Head Neck Surg 23(3):87-91

156. Filipo R, Attanasio G, Viccaro M et al (2012) Hyperbaric oxygen therapy with short duration intratympanic steroid therapy for sudden hearing loss. Acta Otolaryngol 132(5):475-481

157. Körpinar S, Alkan Z, Yigit O et al (2011) Factors influencing the outcome of idiopathic sudden sensorineural hearing loss treated with hyperbaric oxygen therapy. Eur Arch Otorhinolaryngol 268(1):41-47

158. Inci E, Erisir F, Ada M et al (2002) Hyperbaric oxygen treatment in sudden hearing loss after unsuccessful medical treatment. Kulak Burun Bogaz Ihtis Derg 9(5): 337-341

159. Dauman R, Poisot D, Cros AM et al (1993) Sudden deafness: a randomized comparative study of 2 administration modalities of hyperbaric oxygenotherapy combined with naftidrofuryl. Rev Laryngol Otol Rhinol (Bord) 114(1): 53-58

160. Zennaro O, Dauman R, Poisot A et al (1993) Value of the association of normovolemic dilution and hyperbaric oxygenation in the treatment of sudden deafness. A retrospective study. Ann Otolaryngol Chir Cervicofac 110(3): 162-169

Publisher's Note Springer Nature remains neutral with regard to jurisdictional claims in published maps and institutional affiliations. 